\title{
DE BUENOS MEXICANOS, CRISTIANOS, SOLDADOS Y VALIENTES: PUEBLOS CORAS Y HUICHOLES EN LA CONFIGURACIÓN DE UNA REGIÓN, 1840 A 1880
}

\author{
Regina Lira Larios ${ }^{1}$ \\ Universidad Nacional Autónoma de México
}

Ele trabajo busca contribuir a un mejor conocimiento de
indígena en el contexto de las guerras prolongadas que duran-
te la segunda mitad del siglo xix envolvieron al país, no solo
poco conocidos por los contemporáneos al periodo, que en la
mayoría de los casos los redujeron al singular colectivo de "in-
dios/indígenas", sino por los que han emprendido su estudio,
que han dedicado poca atención a las formas de organización
de los pueblos, como a sus dinámicas intra e interétnicas. Lo
haremos enfocando las estrategias y dispositivos políticos que
los pueblos coras y huicholes de la Sierra del Nayar pusieran

Fecha de recepción: 17 de septiembre de 2018

Fecha de aceptación: 8 de febrero de 2019

\footnotetext{
${ }^{1}$ Agradezco los comentarios y críticas de los evaluadores, fundamentales para alcanzar la versión final. Asimismo, agradezco a fray Raúl Robledo y a Patricia Guzmán, del Archivo Franciscano de Zapopan, y a la maestra Glafira Magaña, del Archivo del Arzobispado de Guadalajara, por su generoso apoyo e invaluable labor de clasificación y rescate de fuentes que nos permiten comprender mejor la historia indígena del Nayar.
} 
en práctica durante las guerras y conflictos que entre 1854 y 1873 abrazaron el occidente de México, tanto en el contexto de las confrontaciones entre liberales y conservadores, como durante el movimiento de los "pueblos unidos del Nayarit”, mejor conocido en la historiografía por el liderazgo militar de Manuel Lozada.

Nos planteamos dos objetivos. El primero, con base en fuentes principalmente eclesiásticas y en la documentación fragmentaria hasta ahora publicada, reconstruir dos episodios cuyas temporalidades son definidas por la misma documentación que nos arroja nueva información sobre pueblos particulares que colaboran entre ellos y con eclesiásticos, militares y funcionarios de gobierno, según las coyunturas, lo que permite superar el presupuesto de la "unidad" entre pueblos muy diversos en el plano histórico, étnico y cultural. ${ }^{2}$ Uno, la segunda etapa de evangelización en los pueblos-misiones huicholes a cargo de los franciscanos del Colegio de Guadalupe, Zacatecas, entre 1842 y 1858 ; y dos, la participación de los pueblos coras en la confederación militar de los "pueblos unidos del Nayarit", bajo el mando de Manuel Lozada entre 1858 y 1873 . El segundo objetivo pone a prueba el potencial analítico de la comparación con el propósito de elucidar los dispositivos políticos indígenas más allá de la coyuntura de la Guerra de Reforma y repensar los comportamientos políticos de estos pueblos desde una perspectiva de más amplia duración. Para ello, abordaré cada grupo étnico de manera separada, destacando los modos de interacción, de colaboración y antagonismo entre ambos y con las diversas facciones a las que se vinculan. $Y$ en un primer $y$ último apartado, presento algunos antecedentes históricos que defienden la necesidad de abordarlos de manera conjunta al develar una dinámica política propia de los pueblos indígenas nayaritas

2 Con "pueblo" me refiero tanto a la cabecera como al conjunto de rancherías dispersas y de terrenos que conforman lo que hoy llamaríamos "comunidad". 
cuyos posicionamientos políticos diversos confrontan, negocian y repliegan las acciones de los gobiernos y la presencia del clero en defensa de la autonomía territorial y político-religiosa de los pueblos del Nayar en su conjunto, al mismo tiempo que han sido determinantes en la conformación política de esta región del occidente de México.

\author{
"SOLDADOS Y VALIENTES": \\ ANTECEDENTES DE LA ORGANIZACIÓN MILITAR \\ DE LOS PUEBLOS DEL NAYAR
}

Hay en la sierra del Nayarit una multitud de poblaciones que desde el tiempo de los españoles eran protegidas, en cierta manera, por estos, que les mandaban misioneros que vivieran con ellos, con el fin de sacarlas del estado de barbarie en que están sumidas, dándoles alguna instrucción. Después de la independencia han seguido yendo algunos sacerdotes, de los que solo existen en la actualidad dos franciscanos. Pues bien, creo de la mayor importancia para el porvenir, que el gobierno fije su atención en este punto y dedique algunas sumas en establecer en todos aquellos pueblos, no solo sacerdotes para infundirles moralidad, sino buenos preceptores que den a esta pobre gente, aunque sea la instrucción primaria. Aquellos habitantes son ya a propósito para la guerra, en su mayor parte soldados y valientes; pero les falta civilización, y el día en que llegaran a adquirirla, aunque fuera en corta escala, el gobierno dejaría de tener ese perpetuo enemigo, explotable por su propia ignorancia, y contaría con un apoyo seguro, puesto que le vendría con la civilización el amor e interés a la familia, el conocimiento de sus derechos y obligaciones, el respeto a las autoridades, y conservaría siempre un recuerdo de gratitud hacia el gobierno, que al proporcionarles tales beneficios, daría bien a conocer el empeño de mejorar la condición de él. ${ }^{3}$

3 Carta de Ramón Corona a Mariano Escobedo, 25 de mayo de 1873, en PeÑA NAVArro, Estudio histórico, pp. 341-342. 
Este pasaje, escrito en Guadalajara el 25 de mayo de 1873 por el general de la $4^{a}$ división Ramón Corona, expresándole a Mariano Escobedo su punto de vista sobre la "cuestión de Tepic" -a dos meses de fusilar a Manuel Lozada-, representa un claro cambio en el discurso oficial que ahora concilia estas poblaciones "ya aptas para la guerra" con los valores liberales: la educación, los derechos ciudadanos, la civilización. Pero diez años antes, el discurso era menos optimista. Un diario de Guadalajara defendía que la sierra "que ahora llaman de Álica, poblada por los indios nayaritas, teguames, coras y otros más o menos belicosos, verdaderamente no ha sido conquistada", ni por medio de las armas, ni con el sistema de misiones; y subrayaba el "espíritu de independencia de todos los habitantes de la sierra, tradición la más sagrada de los indios que se sabe la defenderán hasta morir". ${ }^{4}$

La fama de belicosos, indómitos y de soldados valientes no se había forjado de un día para otro. No solo "los" nayaritas -cuyas diferencias eran ignoradas por los que vivían en Guadalajara- habían logrado resistir el orden colonial español hasta 1722 , sino que formaron parte de una organización militar bajo el gobierno de las fronteras que se mantuvo en funcionamiento entre 1590 y 1804, constituyendo las identidades políticas de los habitantes de esta región de occidente que será determinante en la conformación de una identidad regional compartida.

Desde las condiciones de su integración al sistema de gobierno de frontera, las diferencias entre los pueblos coras -mediante conquista militar-y los huicholes - por medio de negociaciones tempranas- se hacen notables. Este sistema de gobierno integró a distintos pueblos de indios a lo largo de una vasta región, desde la costa del Pacífico hasta los valles intermontanos de ColotlánBolaños, sobre la cual se tenía poco dominio al ser atravesada

${ }^{4}$ HDUNAM, Brizuela, “Colonización de la Sierra de Alica”, El País (13 sep. 1861), pp. 1-2. 
por la Sierra Madre Occidental, y cuya incorporación se dio en distintos tiempos ligados a coyunturas particulares. ${ }^{5}$ Por ejemplo, el Gobierno de las Fronteras de San Luis de Colotlán abarcó 25 pueblos, entre ellos los pueblos de Tenzompa, Nostic, La Soledad, San Nicolás, Huejuquilla en los valles intermontanos al oriente, donde se asentaron tempranamente familias huicholas atraídas por la mediación del capitán Miguel Caldera, quien negocia las condiciones de su asentamiento con el virrey Velasco, las familias tlaxcaltecas emigradas y los caciques locales en el contexto de las Guerras Chichimecas y el auge de las minas zacatecanas, que se estabilizan a lo largo del siglo xvir; y también los pueblos de San Andrés Cohamiata, Camotlán, San Sebastián y Santa Catarina en las tierras altas de la porción sureña de la Sierra Madre Occidental, conocida como Sierra del Nayar, de los que tenemos informes detallados de finales del siglo xviII. De estos se decía "se distinguen de todos los demás pueblos de la Frontera", son "más bien formados, tienen un cuerpo más suelto y vigoroso, usan armas de mucho más tamaño y las manejan con mucha más destreza”, y son "mui afectos a los Nayaritas, a quienes dan oculto auxilio en sus alborotos con armas y dinero". ${ }^{6}$ Como súbditos del rey y "afectos" a los nayaritas rebeldes, este doble papel resultó ser una estrategia política exitosa al garantizar el control interno de sus territorios, su participación en las redes de intercambio y comercio regional, al mismo tiempo que se beneficiaron del sistema de regalos y de privilegios por su condición de fronterizos.

\footnotetext{
${ }^{5}$ A esta región histórico-cultural la antropología la denomina el "Gran Nayar". Sobre investigaciones del gobierno de frontera en esta región, véase el texto fundador de Velázquez, Colotlán; y más recientes, Gutiérrez, El gobierno de frontera, y la tesis de GÜERECA, "Las milicias de indios flecheros". En otro trabajo defendí la propuesta de abordar la región de manera conjunta, en su dinámica interétnica y pluridimensional; LiRA, "La organización colonial".

${ }^{6}$ Informes de 1790 en Rojas, Los huicholes, pp. 106 y 100, respectivamente.
} 
La integración de los pueblos "nayaritas" al sistema colonial se llevó a cabo en 1722 por la vía de las armas. Este término se empleaba para designar a los grupos rebeldes -coras, tecualmes, huaynamotecos, tepehuanes y huicholes y otros de los que poco se sabe- organizados desde la Mesa del Nayarit, sede del "Nayarit", Tonati o jefe cora, y lugar de culto donde se conservaban los cuerpos momificados de sus antiguos gobernantes que fungió como "instrumento de cohesión" entre pueblos más allá de la nación cora. ${ }^{7}$ La autoridad de su gobernante y la jerarquía de este sitio se cimentaban en su papel estratégico dentro de un sistema de intercambios ceremoniales y comerciales en el que todos los pueblos serranos participaban. Esta organización ha sido interpretada por Raquel Güereca en términos de un estado segmentario, para dar cuenta de la esfera de influencia del jefe o Tonati, quien "mantiene la superioridad ritual sobre el territorio completo, pero su poder político está limitado a su territorio central". ${ }^{8}$ Durante sus años rebeldes, estos pueblos estaban integrados a la economía regional, como trabajadores de temporal en las minas y haciendas vecinas y como comerciantes

7 Las descripciones de fray Arias de Saavedra son ejemplares; en Calvo, Los albores, pp. 284-309. La expresión “instrumento de unidad” la emplea Hers, "Renovación religiosa", p. 179.

8 Citado en GǗrecA, “Caciques, lenguas y soldados”, pp. 304-331, siguiendo la propuesta de Fargher y Blanton que analiza el modelo de la organización segmentaria desde una perspectiva económica que presenta limitaciones de aplicación al carecer de evidencia documental que la sostenga, y es distinta de la perspectiva estructural desarrollada por la antropología política y aplicada por Phil Weigand en la zona transtarasca del posclásico en Weigand, "Territory and Resistance”, p. 57. Cada una de estas pone a discusión los modos de interrelación entre distintas unidades (grupo doméstico, comunidad, señorío) apelando a distintos recursos (modos de recaudación de ingresos entre centro y periferia o reglas matrimoniales y de filiación que definen reglas de residencia y con ello de colaboración) que detonan alianzas más amplias en ciertas coyunturas. Este modelo ha abierto la discusión sobre las organizaciones políticas de los estados nativos mesoamericanos, por ejemplo, en GuTIÉRREZ Mendoza, "Hacia un modelo general”, pp. 26-67. 
de una serie de productos de la costa, los valles y la sierras, a los que se habían integrado otros como reses, ovejas, caballos, mulas y armas con el saqueo a las poblaciones vecinas. Mas, como lo han planteado Jáuregui y Calvo, "Los nayaritas se sirvieron de esos 'adelantos técnicos' precisamente para adecuarse al entorno colonial, desde una situación de autonomía política y autoctonía religiosa". ${ }^{9}$ La Mesa del Nayarit fue el objetivo militar y religioso de los españoles como estrategia para asegurar el control en la región. Esta dio paso a la fundación del Nuevo Reyno de Toledo y de presidios y pueblos-misión a cargo de los jesuitas en los márgenes del río Santiago y entre los ríos San Pedro y Jesús María, gobernados por un comandante militar designado como "gobernador, protector y teniente de capitán general", y sus tenientes, aunque sujetos en lo político y judicial a la Audiencia de Guadalajara. ${ }^{10}$

Una de las características de este sistema de gobierno fue la creación de compañías de milicias de indios que operaban como corporación al gozar de un estatuto particular ante la ley. A estos milicianos se les otorgó una serie de privilegios que en otras partes de la Nueva España habían sido reservados a la nobleza indígena: exención del pago de tributo -a perpetuidad en el caso de las misiones-, derecho a portar armas, dispensa del pago de alcabala y sisa, cabalgadura a veces con silla y freno y derecho a portar el pendón real y banderas con armas reales. Los coras fueron sujetos a mayores restricciones y estaban bajo vigilancia militar estricta, mientras que las milicias colotlecas gozaron de mayor libertad: sin control sobre las armas de fuego, carcajes y flechas, ni intermediarios entre capitán protector y fuerzas militares. De esta organización surgió la figura de capitán de guerra indio que cada pueblo designaba según sus costumbres.

\footnotetext{
9 Calvo y Jáuregui, "Prólogo", p. xxv.

10 Ortega, "Maravillosa", p. 181. Este proceso ha sido estudiado por MagriÑÁ, Los coras, y más recientemente por GÜERECA, “Caciques, lenguas”.
} 
Sabemos que entre los coras este cargo era hereditario, de modo que esto propiciaba la acumulación de poder y de su esfera de influencia, que entraba en competencia directa con otros cargos; y entre las milicias huicholas, este era responsable de obtener constancias escritas de sus acciones militares para engrosar las listas de méritos y servicios que empleaban ante autoridades locales y virreinales para garantizar la conservación de sus tierras y privilegios. ${ }^{11}$

Entre los siglos XVII y XVIII, el sistema de frontera se extendió hacia los valles altos cercanos a Tepic durante la creación de nuevos asentamientos fundados con indígenas nayaritas bajados de la sierra o con "indios nuevos" hablantes de cora y de "lengua mexicana". ${ }^{12}$ Estos nuevos pobladores también rindieron servicio como milicianos a cambio de hacerles extensivo el sistema de privilegios de los fronterizos de Colotlán; se les ofrecen garantías sobre sus tierras y se les permite cierta flexibilidad en la práctica del culto católico y en la gestión de sus fondos. Esta región fungió como zona de contención de los nayaritas rebeldes, pero también participó en el esquema comercial que operaba desde tiempo antes entre las tierras altas, los valles y la costa; por ejemplo, el libre comercio de sal involucraba a pueblos más distantes, como los huicholes que se abastecían en la costa Pacífico y la comercializaban en los centros mineros de la vertiente oriental de la sierra, como Bolaños, y debió entretejerse mediante de vínculos parentales durante los reacomodos poblacionales. A partir de la fundación del puerto de San Blas,

11 Retomo diversos datos de GüERECA, que hasta ahora es la investigación más completa y novedosa sobre el tema, "Las milicias de indios flecheros", caps. 3 y 4, pp. 148-198; sobre méritos y servicios, RoJas, Los buicholes, p. 61.

${ }_{12}$ Sobre fundaciones en la región de Acaponeta, Tello, Crónica, p. 214. Según informe de finales del siglo xviı los pueblos milicianos hablantes de cora eran San Blas, San Pedro, Saycota, San Buenaventura, Milpillas y Picachos, y de "lengua mexicana" eran San Diego, Huajicori, Quiviquinta y San Francisco del Caimán; en "Las tropas de indios flecheros", en Boletin del AGN, pp. 742-744. 
las milicias de fronterizos eran empleadas como vigías, marineros y en la defensa contra los piratas que asolaban las costas. ${ }^{13}$

Junto con los demás fronterizos, los milicianos huicholes participaron como mediadores e intérpretes y en acciones ofensivas y defensivas para apoyar la represión de tumultos, perseguir salteadores o ladrones en las jurisdicciones vecinas de Zacatecas, Nayarit, Nueva Vizcaya, Venado, Mexquitic, Saltillo, Guanajuato y San Luis Potosí. Cuando sus privilegios eran amenazados o sus tierras invadidas, los fronterizos colotlecos se levantaban en armas para defenderlas, demostrando gran capacidad de movilización y de negociación con las autoridades coloniales. Según un informe de 1783 del cura de Colotlán:

Y así señor en aquellos tiempos, vivían los Capitanes Protectores poseídos de grande temor, y pusilanimidad sin poder jamás dar el expdte. necesario a sus empleos y obligaciones: Pues cuando querían levantar la voz para administrar Justicia les amenazaban los Indios, o con asechanzas, o con la misma muerte, como se experimentó con el Capn. Silva, si no cumplían la voluntad de ellos mismos. En esta consternación, siempre quedaron impunes los delitos, sin Castigo, los homicidas; sin formarse proceso a los Ladrones; sin requerirse los escandalosos; $y$ finalmente sin administrarse Justicia. ${ }^{14}$

Este tipo de pasajes, abundantes en las crónicas, también hacían referencia a los "mulatos, negros y otras castas" que se refugiaban entre los fronterizos, demostrando una disposición para establecer alianzas fuera del grupo étnico que no solo se daba dentro de sus territorios sino también hacia fuera..$^{15}$ Los coras, por ejemplo, denotan una actitud defensiva pero también ofensiva, aprovechando las disputas entre autoridades españolas para

\footnotetext{
13 PInZón, Acciones y reacciones, pp. 197-198.

${ }^{14}$ Informe de 1783 en Velázquez, Colotlán, p. 58.

15 Por ejemplo, Informe de 1783 en Velázquez, Colotlán, p. 39; Arlegui, Crónica, p. 180.
} 
establecer alianzas interétnicas y también interclasistas. Diversos levantamientos fueron documentados en 1723, 1724, o en 1758 cuando el líder Manuel Ignacio Doye se alía a un comandante español, con autoridades de diversos pueblos coras y comandantes de tierras bajas en contra de los jesuitas; otro levantamiento en 1767 lo condenaría al destierro en La Habana. ${ }^{16}$ El famoso levantamiento del líder "mesiánico" "Máscara de Oro” entre 1801 y 1802, cuya identidad nunca fue revelada, implicó la participación de más de 23 pueblos de las tierras bajas, los valles y la sierra nayarita, en la que se sospechó la colaboración de miembros de la élite criolla, como el Conde de Miravalles, que toman una bandera roja de la Virgen de Guadalupe como estandarte de la rebelión y proclaman la llegada de un nuevo rey con una corona de espinas, lo que desemboca en el encarcelamiento de 237 prisioneros, muchos de estos desterrados hasta $1809 .{ }^{17}$ Esto para mostrar que los pueblos serranos y de los valles comarcanos mantuvieron vínculos de colaboración y de antagonismo por medio de redes de intercambio y parentesco, y también de guerras y disputas por tierras, pastos, ganado, maderas y agua, que habilitaron alianzas regionales, interétnicas y posiblemente interclasistas, que no son un fenómeno decimonónico, sino que por lo contrario, son constitutivas de una dinámica regional particular de larga data.

A pesar de las intenciones del Conde de Revillagigedo en 1792 de desmantelar el gobierno de frontera e integrarlo al orden político y administrativo de Guadalajara, para 1806 no era aún un hecho consumado. Se había logrado unificar el Nayarit, el partido de Bolaños y las fronteras de Colotlán en un mismo gobierno; su gobernador administraba desde Colotlán, delegaba la administración local a un teniente, y el cargo de "capitán protector” había dejado de existir. Por falta de insumos para

16 Caso analizado por Hers, "Renovación”.

17 Castro, "La rebelión”. 
establecer las demarcaciones territoriales, no logra concretarse el proyecto que pretendía dividir la región en once subdelegaciones, que para entonces aún gozaban de ciertos privilegios, como la exención de tributo. Un informe de 1807 advierte sobre "la licenciosa vida en que se mantienen [los naturales] entregados a toda clase de vicios, sin subordinación, temor, ni respeto a las continuas amonestaciones de los PP. Misioneros, quienes penetrados del más ardiente celo, deben que sus tareas y fatigas no producen el efecto que desean". ${ }^{18}$

\section{PRELUDIO: LOS PUEBLOS DEL NAYAR, ENTRE GUERRAS}

Durante el movimiento insurgente las milicias indígenas participan a favor y en contra de los realistas. Según el relato del comisario de las misiones del Nayarit en 1812, los coras pelearon del lado realista, mientras que los de Huaynamota e Ixcatán del lado insurgente. El cura insurgente José María Calvillo contó con un ejército de 8 a 10000 flecheros de Colotlán; los huicholes de San Sebastián, San Andrés y Santa Catarina pelearon en ambos bandos. ${ }^{19}$ Lo que fue parejo fue el saqueo y la destrucción de estos pueblos, algunos abandonados para siempre. Las ocho misiones coras, que desde la expulsión de los jesuitas habían sido retomadas por los franciscanos de la Provincia de Santiago de Jalisco, se fueron abandonando poco a poco, tanto por los recortes

${ }^{18}$ El último capitán comandante fue Gregorio Pérez, quien gobernó hasta 1804. Este informe de Tomás Martín Ballesteros (Jerez, 30 de abril de 1807) es parte de un expediente que reúne 34 testimonios sobre el gobierno de las provincias de Colotlán y Nayarit, AGN, Provincias Internas, vol. 257, exp. 26, años 1806-1807.

19 "Informe rendido al Provincial de los Franciscanos de Santiago de Jalisco por el P. Comisario de las Misiones, Fr. Ignacio Rico, a la Comisión de Gobernación del Congreso del Estado", 7 de junio de 1824, en Santoscor, Obras completas, pp. 160-165; "Informe de Fray Rudesindo Angles sobre las Misiones de Nayarit en 1812”, Guadalajara, 29 de marzo de 1812 en López, Algunos documentos, pp. 47-63. 
en los gastos para su manutención como por la ley de expulsión de españoles de $1828 .{ }^{20}$ La única misión que se mantuvo con presencia continua fue Jesús María, a cargo de fray Rudesindo Angles, que la ocupa desde 1793, cuando fue designado presidente de las misiones en el contexto del programa que pretendía extinguir el gobierno de fronteras. Angles ocupó esta posición hasta su muerte en torno a 1826, cuando la retoma fray Vicente Buenaventura Cárdenas. Estas misiones se integraron al séptimo cantón de Jalisco.

Sobre los pueblos fronterizos huicholes de la vertiente oriental de la sierra, la única misión fundada en territorio serrano fue la de San Sebastián Tezocuautla (hoy Teponahuastlán), con sus dos pueblos de visita, San Andrés Cohamiata y Santa Catarina Cuexcomatitlán, a cargo del Colegio Apostólico de Nuestra Señora de Guadalupe. Fragmentos en los archivos permiten reconstruir la cronología de su ocupación. ${ }^{21}$ La misión de San Sebastián fue fundada en 1733, cuando se segregó de la doctrina de Chimaltitán, y se mantuvo activa, con visitas regulares a los pueblos de visita, hasta 1811, cuando fray José Gil de Rivas la abandona por unos meses durante el movimiento insurgente. Desde entonces, se visita esporádicamente por curas de Bolaños y Chimaltitán y por orden del obispo Ruiz de Cabañas, hasta que entre 1816 y 1826 las retoma el presbítero Juan Llanos y Valdez. Una vez más se abandonan, con visitas esporádicas encargadas por la mitra. Una de estas en 1833 a cargo de fray Ángel Martínez, quien desempeñara un papel importante en la reactivación de las misiones 10 años más tarde. Durante estas primeras décadas, se entiende como pueblos de huicholes a los tres mencionados más arriba y ubicados en las serranías,

20 AHFZ, Prov. SS Fco. Stgo. Mx, "Información histórica sobre la atención misionera de los coras desde el siglo xvi hasta hoy”, de Fray Alberto Campos Hernández, 4 de diciembre de 1979.

${ }^{21}$ Esta cronología deriva del cotejo de diversas fuentes documentales del AHFZ, CAGZ, G, $M N$, exp. 37, núm. 23. 
pues los terrenos de los valles y cañones intermontanos donde se ubican pueblos como Camotlán, Huajimic, Nostic, Tenzompa y La Soledad, en su origen pueblos fronterizos huicholes, eran codiciados por los vecinos, de modo que para 1826 es difícil determinar si son pueblos de "castas" o aún de huicholes. ${ }^{22}$ En principio, todos estos formaron parte del octavo cantón de Jalisco, que absorbió la antigua frontera de Colotlán, pero las colindancias entre cantones eran todavía difusas.

Entre las décadas de 1830 y 1850, las tensiones en los pueblos de los valles altos del séptimo cantón se recrudecen. Esto se liga a los cambios estructurales que se producen desde las primeras décadas del siglo xIX en el medio rural que vemos en otras partes del territorio nacional. La crisis económica había acelerado la transformación de la hacienda que incorpora cultivos comerciales y da paso a una nueva generación de empresarios que conquistan las tierras de los valles altos de los pueblos fronterizos aptas para los nuevos cultivos que pierden su estatus de protección en plena década desamortizadora, que además el alto clero busca recuperar. Este primer foco del conflicto es determinante en la organización de los pueblos sublevados en la década de 1850, que se ha identificado como el corazón del conflicto agrario y del que surgen importantes liderazgos del movimiento de los Pueblos Unidos de Nayarit, del que tenemos noticias desde 1857.23

En los pueblos serranos, la década de 1850 inició con una gran sequía en que, según recuerda el padre Ignacio Castro de Tepic, "salieron en bandada los naturales a buscar el alimento por toda la costa (en las haciendas de caña de azúcar y de arroz); esa época fue quizás la única de su vida que trabajaron tantos jóvenes robustos que por lo regular pasan la vida en la ociosidad e indolencia". ${ }^{24}$ Para entonces la sierra es amenazada por

${ }^{22}$ Informe de Rudesindo Angles de 1822, en Rojas, Los huicholes, p. 116.

23 Van Oosterhout, "Confraternities and Popular", p. 102.

${ }^{24}$ Ocurre en 1852. AHAG, Gobierno, Parroquias, Tepic 1854-1876, Carta de Ignacio Castro, 26 de abril de 1854. 
las correrías de los indios apaches que llegaron hasta el pueblo huichol de San Andrés, la sierra de Durango y de Zacatecas. Para 1854, el bandidaje es crónico y abundan referencias a robos, incendios y asesinatos en diversos puntos de la región del Nayar, hasta entonces aparentemente inconexos. La polarización de la sociedad mexicana en los albores de la revolución de Ayutla adquiere su expresión en la Sierra del Nayar, y los pueblos coras y huicholes se ven involucrados en este conflicto de múltiples facetas y escalas, cuyos posicionamientos políticos y formas de involucramiento intentaremos elucidar.

Los franciscanos son sin duda los que mejor llegan a conocer a los nayaritas y sus diferencias. Los distinguen por su vestido, fisionomía, color, estatura e idioma: el huichol se habla en San Andrés, Santa Catarina, San Sebastián y Guadalupe Ocotán; en Azqueltán se habla el tepehuán; en Mezquitic, Huejuquilla, Huaynamota y Camotlán el mexicano; en La Mesa del Nayarit, Santa Teresa y Jesús María el cora. ${ }^{25}$ Son también conocedores de la historia colonial: documentos antiguos originales y transcritos e informaciones diversas son sigilosamente resguardadas; por ejemplo, el informe de 1792 del virrey Revillagigedo sobre las fronteras se encuentra transcrito a mano en el archivo franciscano. ${ }^{26}$ Para mediados de la década de 1850 , según estimaciones estadísticas propuestas por fray Miguel Cázares, encargado de la misión de Huaynamota, calcula a la población huichola entre 9 y 10000 , a la cora entre 3000 y 3500 , a los mexicanos entre 500 y 800 , y a los tepehuanes entre 600 y 1000 . Con ello, estima a la población indígena nayarita entre 13100 y 15300 , repartidos

${ }^{25}$ HDUNAM, Castro, "Visita del...”, El Siglo Diez y Nueve (21 jun. 1854), pp. 1-2; AHAG, Gobierno, Parroquias, Tepic 1854-1876, "Misiones visitadas personalmente por el Obispo Don Pedro Espinosa”; y en Rojas, Los huicholes, pp. 156-157.

${ }^{26}$ Este fue publicado en El Siglo Diez y Nueve (21 ago. 1843), pp. 2-3. Copia transcrita en AHFZ, CAGZ, G, $M N$, exp. 37. 
entre los estados de Jalisco (para entonces incluye a Tepic), Durango y Zacatecas. ${ }^{27}$

Mas, aunque los franciscanos llegaron a conocerlos mejor, las clasificaciones políticas y sociales en la documentación gubernamental no hacen distinción entre ellos: son indios primitivos y salvajes. Desde la independencia, decía un articulista de la época, "México no volvió a pensar en el Nayarit, hasta que Lozada le alzó un cáustico en 1850 ”. ${ }^{28}$ El mismo párroco de Tepic reconocía en 1854: "sin embargo de hallarse, casi en el corazón de la república se encuentran en la actualidad fuera del alcance de las autoridades, tanto en lo religioso como en lo político. Hablar de sus aduares, de sus costumbres, de su moral o de su civilización, es para nosotros lo mismo que tratar de las hordas errantes de los desiertos de África, parece una ponderación pero lo cierto es que nada se sabe de esos infelices indígenas" ${ }^{29}$ Este olvido y la incomprensión del campo político indígena durante todo el siglo xix habrían de costarles caro a los defensores del naciente Estado liberal mexicano, pues los prejuicios raciales de la época tienen un impacto negativo en la posibilidad de hacerse en sus márgenes mediante alianzas potenciales con los pueblos serranos con los se habían mantenido alianzas estratégicas durante dos siglos, y como se supo hacer en otros puntos de la República. ${ }^{30}$ A diferencia de los liberales jaliscienses, los conservadores tepiqueños aprovecharon la coyuntura y capitalizaron el descontento de los pueblos nayaritas, sus vecinos históricos de los que sin duda sabían eran

${ }^{27}$ En "Inventario, inspección y registro que ejecutó fiel y pormenorizadamente en los templos del Nayarit el Padre Manuel María Estragues. T. de Propaganda Fide en mayo de 1884", en López, Algunos documentos, p. 107.

${ }^{28}$ HDUNAM, Brizuela, "Colonización de la Sierra de Alica”, El País (13 sep. 1861), pp. 1-2.

29 AHAG, Gobierno, Parroquias, Tepic 1854-1876, Carta de Ignacio Castro, 26 de abril de 1854.

30 Por ejemplo, en Puebla, Thomson, El liberalismo; en Guerrero, GuardiNo, Campesinos y política. 
soldados y valientes (y belicosos e insumisos), que encauzaron su lucha por la defensa de un proyecto conservador de nación que durante esos años adquiere forma. La mitra de Guadalajara y los misioneros franciscanos también aprovecharon la coyuntura y vieron en la Sierra del Nayar una oportunidad para fortalecer su presencia en la región. Con el apoyo financiero del gobierno de Jalisco, y "por recomendación del presidente de la República”, se reconoce como urgente apoyar la revitalización del proyecto misional. ${ }^{31}$

\section{PORQUE “SOMOS CRISTIANOS”: \\ LA SEGUNDA ETAPA DE EVANGELIZACIÓN FRANCISCANA EN LOS PUEBLOS HUICHOLES (1842-1858)}

El comisario de misiones franciscanas del Colegio de Guadalupe en Zacatecas, Rafael de Jesús Soria, advertía al obispo de Guadalajara en 1844: "intentar quitarles a los indios un palmo de tierra, es tocarles una fibra muy delicada". ${ }^{32}$ Entradas como esta en su diario nos ofrecen indicios sobre la situación agraria de los pueblos huicholes y la actuación de los frailes franciscanos que entre 1842 y 1853 emprendieron una segunda etapa evangelizadora, tras casi 30 años de ausencia.

La relación parece iniciar con términos claros. En un documento firmado en la misión de San Sebastián por el gobernador y autoridades del pueblo de San Andrés de 1843 declaran:

[...] prometemos llevar toda armonia con los de la congregacion de -estan(?), esforzarnos en qe en este punto se reunan las $200 \mathrm{fam}$ con casas fabricadas y residencia fija en ellas, qe nuestros hijos y respectivamente todos los del pueblo asistiran a la enseñanza qe se

31 AHAG, Gobierno, Otras diócesis, Tepic 1849-1850, "Sobre sínodos de los misioneros de Nayarit, 1850”, 21 de junio de 1853.

32 SORIA, "Diario", p. 438. 
de en las escuelas o en la Iglesia, sin qe en lo sucesivo se reciba pr VS queja o se pueda recelar qe se repitan en S Andres ni los viajes al Peyote, ni las fiestas de calihuey, ni cosa alguna de las q reprueba la sagrada religion, y nos desaprueban nuestros Padres los misioneros, a quienes respetaremos y veneraremos. Pidiendo a Ud q dispense a este Pueblo los motivos que ha dado de disgusto y desason a su respetable persona. ${ }^{33}$

Aunque no sabemos las condiciones en las que se expide este documento en el que hacen tales promesas, sabemos que al tomar estos pueblos bajo su custodia y protección, los frailes emprendieron acciones para su defensa, desaconsejando se promueva el establecimiento de familias “de razón” para su “civilización” y para la protección de sus terrenos. ${ }^{34}$ Una de las principales zonas de conflicto en la década de 1840 se concentraba en el extremo septentrional del territorio huichol, en los terrenos entre la hacienda de San Antonio de Padua, los pueblos huicholes de San Andrés y Santa Catarina, y los pueblos de Huejuquilla, Tenzompa, Mesquitic y Nostic, que presentaron numerosas denuncias porque su dueño, Benito del Hoyo, los "hostiliza diariamente", incendiando sus jacales, destruyendo sementeras y había dejado de pagarles por el uso de sus montes, quedando "impune" por ello. ${ }^{35}$ Desde su llegada, fray Soria intercedió ante el prefecto de Colotlán, Ignacio Suárez, a favor de los de Santa Catarina evitando que se pusieran en posesión del hacendado tierras reconocidas en los títulos de Santa Catarina, el único de los tres pueblos que los posee. Entradas de su diario

33 Carta de 8 de abril de 1843 firmada por Ignacio Basilio, Nicolás Benito, Ignacio Mijares, Ignacio Cruz y Bartolo Carrillo, AHFZ, CAGZ, G, $M N$, exp. 37, núm. 24.

34 Carta de Rafael de Jesús Soria al obispo de Guadalajara, 6 de diciembre de 1845, "Estado de las misiones huicholas y sobre el estado jurídico de ellas", AHFZ, CAGZ, G, $M N$, exp. 37.

35 Rojas, Los buicholes, pp. 134-135. 
de 1844 registran parcialmente el curso de las acciones. Mayo: "que es inevitable el despojo de tierras a los catarineros". Octubre: "atendiendo a los resortes que tiene el hacendado, y no hay dinero para hacerle oposición, que el último recurso que me queda es ver si el señor Obispo se interesa con el señor Escobedo, para que este señor influya para que se atienda la justicia de los indios". Noviembre: "Que en cuanto a los huicholes, el señor Obispo adoptó el único remedio que en mi concepto hay, y es que se tome por providencia gubernativa el sacar gratis del Archivo del Supremo Gobierno testimonio de los títulos de sus tierras desde la conquista, y se comisione un sujeto que coteje estos títulos con los de la hacienda de San Antonio, y se adjudiquen los terrenos a quienes corresponden”. Al padre Pacheco: "que impuesto por el padre Guardián de los motivos que lo impulsaron a salir de Santa Catarina, he tomado las medidas que me parecen conducentes al restablecimiento de la paz (le refiero lo que sigo antes acerca de los títulos), también le digo las noticias del padre Vázquez, que se vuelva, y que si están revolucionados los pueblos se estén ínterin en los lugares limítrofes". Al padre Vázquez: "que su carta del 29 del pasado me deja consolado al ver que los indios lo han invitado, le digo lo que al padre Guardián acerca de los títulos de las tierras [...] que no fui a Guadalajara por que el señor Obispo tomó a su cargo el asunto, sin embargo que también voy a hacer una exposición al señor Gobernador". 36

$\mathrm{Al}$ retomar estas misiones, fray Soria se lamentaba sobre el estado de sus "creencias, supersticiones e idolatrías" -lo que le lleva a sugerir que se trata de "uno de los preziosos restos que quedan del Anahuac"-, y de su inextricable vínculo con el

36 Todas estas referencias son de su "Diario", p. 438, pp. 444-451. Es probable que de estas iniciativas se haya generado una copia de los títulos del pueblo de San Andrés de 1809, cuyos originales se habían perdido, y que hoy resguarda el archivo franciscano con un plano, en que se entiende que el trámite no pudo ser completado al haberse atravesado la guerra insurgente. 
territorio: "en lo muy poco que conocen al Dios verdadero es también su adoración supersticiosa y sus obligaciones y sacrificios son también a dioses falsos, en estos creen, de estos esperan y estos aman porque a estos atribuyen los bienes temporales que poseen" ${ }^{37}$ Como él, los misioneros que lo acompañaron, mientras conquistaban su confianza, documentaron con atención lo que se les permitía ver o lo que les contaban ("He observado" o "De esta nada he visto, es noticia de oído", se precisa), ${ }^{38}$ ofreciendo un retrato vivo y rico de la vida ritual, pues a diferencia de los vecinos coras, acostumbrados a los métodos jesuitas que los obligaron a esconder su práctica ritual, los huicholes no se escondían para hacer sus fiestas, por lo menos en estos primeros años. Escriben sobre el "gobierno civil de los pueblos": con gobernador, alcalde, capitán de guerra, sargento mayor, alguacil, sus topiles y auxiliares, que se reúnen en "consilios", y que cada año son elegidas el 4 de octubre. Reconocen la "autoridad de los viejos" que mandan a los que "ejercen oficios de jueces" o "cargos", como ya entonces se les llamaba, confirmados en la cabecera del cantón en Colotlán a donde iban a "feriar sus varas", instauradas con danzas el mes de enero. ${ }^{39}$

Escriben sobre sus fiestas: la de las Varas, el Sol, el Venado, el Peyote y de la Vaca. Sobre la parafernalia ritual: flores, alimentos de maíz, peyote, chocolate, monedas, figuras en cera, jícaras bordadas con cuentas, figuras de barro en miniatura, flechas,

37 Citado en Martínez, Introducción a "Diario", p. 434.

38 Herrera, "Memorias de la misión de San Andrés Cohamiata", pp. 152 y 149 respectivamente, estimado por el autor entre 1853-1872. Y "en la década de los años 1860" según Meyer, Manuel Lozada, p. 198. Por mi lado, estimaría su redacción entre 1842 y 1853, periodo de aproximación tímida que describo, basada en el hecho de que son mencionadas las poblaciones de Mesa del Venado y Tierras Coloradas que los franciscanos renombran en 1853 (Buen Pastor y Santa Gertrudis respectivamente).

${ }_{39}$ El término "cargo" aparece en "Memorias", p. 144. Las referencias al gobierno civil, en RoJAs, Los huicholes, pp. 139-188; y en AHAG, Gobierno, Parroquias, Tepic 1854-1876, "Relativo a las Misiones de Nayarit" de 1856. 
arcos en miniatura, plumas, sartas de cuernos de venado, tejidos de lana de colores, canutitos de algodón, pedernales envueltos, ídolos de cantera. Y otros detalles: untan sangre de venado y de vaca, queman incienso, tiran cohetes, dan repiques de campana, se arrodillan ante la vaca que han adornado con flores para matarla o ante las varas o bastones de las autoridades que colocan en un altar adornadas de flores y con velas ardiendo. ${ }^{40}$ En sus "fiestas”, término también empleado por los franciscanos, bailan el "mitote" y los viejos "en unos bancos con respaldo" y en "tono funesto comienzan a cantar". ${ }^{41}$ No solo practicaban sus fiestas sino que mantenían el ciclo de intercambios comerciales con productos como sal, ocote, miel y aves con poblaciones desde la costa del Pacífico hasta el Real de Bolaños, y ceremoniales entre lugares de culto y recolección entre la Mesa del Nayarit y el desierto de San Luis Potosí en una vasta región del occidente y norte del país:

[...] q desde el mes de Septe y octe se previenen para ir en especie de romería desde estos puntos hasta internarse al estado de S Luis Potosi, comienzan por abstenerse de alimentos con la circunstancia q los q van la primera vez desde q salen de su rancho o casa van con los hojos vendados hasta q llegan al punto donde caban el peyote sin permitir q se quita la benda por la idea de q si se la quitan queden ciegos. Se abstienen los mas de alimentos y de usar sal en lo que toman, llevan varios presentes a aquellos puntos. A su venida son muy bien recibidos por todos, principalmente por los que cuidan el calihuey (lugar destinado pa sus funciones) aquí reunidos todos los que fueron permanecen hasta q vienen los q van a llevar noticias y presentes hasta una cueva q ecsiste en la mesa del Nayarit venidos q son comienzan sus solemnidades, pues ya

40 Tomado de documentos diversos del AHFZ, publicados en Rojas, Los buicholes, pp. 139-188.

${ }^{41}$ Herrera, "Memorias”, p. 148. 
pa esto esta prevenido el mismo peyote fermentado para beberlo a mas del que comen sin fermentar. Una noche antes de concluir la fiesta tres indios de los más viejos y de los principales comienzan el canto del mitote [...]. ${ }^{42}$

Fueron muchos los frailes que desfilaron por estas misiones; pocos aguantaron el estilo de vida según sus quejas amargas en la correspondencia con el Colegio en Zacatecas. En sus cortas o largas estancias se dedicaron a la reedificación de las iglesias sobre antiguos cimientos en San Sebastián, Santa Catarina y San Andrés. Ya ganada su confianza, empezaron a introducir algunos preceptos cristianos; algunos ya habían sido integrados a la vida ritual nativa (las sagradas imágenes y los crucifijos eran "pastores o vaqueros de sus ganados y los tienen junto a sus ydolos que adoran"). ${ }^{43}$ Un huichol de San Andrés le decía al padre que insistía en que abandonase sus prácticas idólatras:

No te canses nosotros no conocemos mas que al sol y al diablo, ese Dios que tu dices no lo conocemos, ni lo hemos de dejar porque el nos da de comer, el nos da la luz, con el sol trabajamos, buscamos nuestros alimentos, todo con el sol, mira la noche ni el agua hallamos, si no mas noche ya nos hubieramos muerto, por eso creemos que el sol nos quiere y para que no se enoje le hacemos fiestas. ${ }^{44}$

No lograron aprender la lengua, pues les resultaba "dificultosísimo" "pronunciar alguna expresión del dialecto de ellos, especialmente porque truncan las voces omitiendo sílabas y letras

${ }^{42}$ Rojas, Los huicholes, p.164. Es la descripción más antigua hasta ahora encontrada del viaje al desierto de San Luis Potosí.

43 Informe de fray Vicente Buenaventura Cárdenas de 1839 en Rojas, Los buicholes, pp. 124-126.

${ }^{44}$ Herrera, "Memorias", p. 148. 
en principio y fin de las palabras", ${ }^{45}$ de modo que enseñaban en castellano, por medio de intérpretes, o "haciéndoles repetir hasta que la retienen". ${ }^{46}$

Uno de los logros de los frailes fue la fundación de una cuarta misión, la de Guadalupe Ocotán, a pesar de las tensiones entre las familias que querían “formar población aparte” y el gobernador de San Andrés, quien solicitaba a fray Miguel de Jesús María Guzmán los atendiera “contra las pretensiones de los de Ocotán para que el Pueblo no quedara abandonado. ${ }^{47}$ Fundada sobre un antiguo asentamiento, en esta misión se puso mayor énfasis en la enseñanza de la advocación mariana en el culto a la Virgen de Guadalupe y también se enseña "el respecto de las leyes civiles porque estos quedan mas en contacto con pueblos de razón y es por necesidad que sepan siquiera el reglamento económico a que se intenta arreglarlos". ${ }^{48}$ Esta fundación reforzó la presencia huichola en el segundo foco de conflicto agrario en la parte sudoccidental de su territorio, en la colindancia entre esta misión, el pueblo de San Sebastián, el pueblo de Huajimic y la hacienda de Camotlán. Al pueblo de San Sebastián se unen los de Ostoc, a quienes "no les queda mas de el puro terreno del fundo legal”, amagados por Joaquín Cantabrana y Gerónimo Sorio, que disputaban los derechos sobre sus tierras, apoderadas por la hacienda de Camotlán desde la Independencia; al mismo tiempo son amenazados por el "patrón” de la capellanía del Tule, D. Pardo, que les exige entreguen los terrenos a sus

${ }^{45}$ Carta de Fr. Guzmán, 26 de septiembre de 1853, AHFZ, CAGZ, G, MN, exp. 37, núm. 225.

${ }^{46}$ Cuestionario contestado por un comisario de misiones de infieles, 1845 , en Rojas, Los huicholes, pp.143-146. Se menciona a un intérprete que auxilia en la misión de San Andrés en 1853, Encarnación Ortega, en Carta a Fr. Miguel de Jesús María Guzmán, 20 de noviembre de 1853, AHFZ, CAGZ, G, MN, G, $M N$, exp. 37, núm. 55.

${ }^{47}$ Carta de Fr. Guzmán, 25 de diciembre de 1852, AHFZ, CAGZ, G, MN, exp. 37, núm. 73.

48 “La Misión de San Sebastián”, AHFZ, CAGZ, G, MN, exp. 37, núm. 73. 
arrendatarios. ${ }^{49} \mathrm{El}$ entonces comisario de misiones, fray Ángel Martínez, temía que los de San Sebastián terminaran como los de Ostoc, y se preguntaba: "será suficiente este pequeño terreno para la habitación de mas de 700 huicholes que componen este pueblo?". ${ }^{50}$ En este contexto intercedió de nueva cuenta ante el obispo Aranda para buscar el "influjo de la autoridad civil" pues aunque los pueblos "de tradición saben lo que les pertenece, se quejan de que se les introducen en ellas personas extrañas invadiéndoles lo suyo, y así entiendo que convendría mucho comprometer de ante mano a favor de ellos y para que les dieran sus títulos sin que en la demarcación de terrenos se cometiera injusticia” ${ }^{51}$ Esta intervención les resultaba obvia y necesaria: "Tampoco el mismo Supremo Gobierno del Estado podría creer fuera de razón o inútil estender su amparo a esos infelices, y en las circunstancias actuales quizá sería una medida de Estado para que puede embarasar la alianza que es de temer y aun ya se vocifera que forman los Apaches con los del Nayarit". ${ }^{52}$

Fray Felipe de Jesús Muñoz describe el "carácter de los Huicholes": "muchos lo tienen pr docil y afable, pr qe aparecen apasibles y timidos pero en mi concepto, es terrible, caprichoso y tenas". ${ }^{33}$ Una vez consolidada su presencia con métodos que en poco variaban de los del siglo anterior, empezó el derribamiento de los templos que para 1853 sumaban $11,{ }^{54}$ la prohibición de

\footnotetext{
49 Rojas, Los buicholes, pp. 133-134.

50 "La Misión de San Sebastián”, AHFZ, CAGZ, G, MN, exp. 37, núm. 73.

${ }^{51}$ Carta al obispo de Fr. Vázquez, 22 de junio de 1852, AHFZ, CAGZ, G, $M N$, exp. 37, núm. 225.

${ }^{52}$ Carta al obispo de Fr. Vázquez, 22 de junio de 1852, AHFZ, CAGZ, G, $M N$, exp. 37, núm. 225.

53 Rojas, Los huicholes, p. 163.

${ }^{54}$ El primer derribamiento ocurrió en Santa Catarina el 25 de diciembre de 1852. También se mencionan derribamientos en: San Sebastián, Ocota, San Andrés, Cohamiata, San José, Santa Gertrudis, otro en los límites de la misión de Guadalupe Ocotán. Se ordena el derribamiento de Pochotita y Las Latas (en Santa Catarina), pero no sabemos si se ejecuta.
} 
las ceremonias, y se refundan pueblos con nombres nuevos (Tierras Coloradas es renombrada Loreto, Mesa del Venado renombrada Buen Pastor). Además, toman control sobre el proceso de designación de las autoridades locales regalando obsequios a los nuevos funcionarios, mermando la autoridad de los ancianos que los designaban por medio de sus "consilios".

Mas esta intensificación del control franciscano es contrarrestada. El gobernador "interino" de San Sebastián y autoridades acompañantes escriben en noviembre de 1853 a un señor de nombre Agustín Ramos, ciudadano de la villa de Colotlán, para que interceda a su favor ante el jefe político de Colotlán:

Sor. D. Agustin Ramos, Pueblo de San Sebastian de 1853= Nosotros los naturales de dicho pueblo, José Lozano de los Angeles, Alcalde Juan y Santos Carrillo y demás yndigena del mismo pueblo nos presentamos y decimos ante $\mathrm{V}$ reconociéndolo como uno de nuestros antiguos padres pasa que por empeño de $\mathrm{V}$ nos presente ante el Sor. G. I... no queremos mas de el P. Vazquez Guadalupe por que estos Sres hasta las costumbres nos quieren quitar, como son las fiestas del peyote, la fiesta del tiempo que comemos la calabaza, el tiempo que comemos los helotes, todo esto nos quieren quitar, todo esto que hacemos no es otra cosa mas de dar gracias a Dios que mas ha dado un pan que comer esto le pedimos o damos las gracias en nuestra lengua o nuestro idioma por que no podemos mas en nuestra lengua que es el orden por donde podemos pedir a Dios a darle gracias porque somos cristianos, no como dicen nuestros Padres que tenemos al presente pues dice que no somos cristianos que no estamos bautizados sabemos que hay Dios en los cielos y en toda la tierra y en todo lugar esta queja es por todos desde el Gobernador, Alcalde, Alguacil mayor Capitan de guerra y demás común del pueblo. No sabemos firmar. ${ }^{55}$

55 Carta de Agustín Ramos, 16 de noviembre de 1853, AHFZ, CAGZ, G, MN, exp. 37, núm. 225. 
Las autoridades del año siguiente, "los malos jueces de ese año" ${ }^{56}$ les llaman los frailes, les prohíben celebrar matrimonios, bautismos y entierros. Diez años de convivencia con los franciscanos llevaban a los firmantes a defender que hacer la fiesta equivalía a dar gracias a Dios, y con base en este lenguaje común, plantearon sus demandas a las autoridades de Colotlán como cristianos. Mas para los frailes la cuestión era irresoluble (asisten a la doctrina y a la misa, pero también a las fiestas de sus ídolos; bautizan a sus hijos, pero los padres no apartan a los hijos de la idolatría) y la contradicción, insuperable. Se exige el retiro de fray José Guadalupe de Jesús Vázquez, el único fraile que permaneció de modo continuo en las misiones por diez años. ${ }^{57}$

Esta estrategia de repliegue se ve favorecida por la coyuntura nacional: sus servicios como milicianos son requeridos por las autoridades cantonales y estatales ante la nueva oleada de violencia que se propaga por toda la región. Los puntos de conflicto agrario, sin ser atendidos, habían acumulado tensiones. Desde Huajimic merodean multitud de "ordadas", además de los "vandidos que andan por el río de Alica"; y los de Tepic, Bolaños y Huejuquilla se habían pronunciado a "favor de los de Guadalajara" ${ }^{58} \mathrm{Y}$ en octubre de 1854, un grupo de rebeldes no identificados asesina al hacendado Benito del Hoyo, a tres de sus hijos y a 13 empleados de la hacienda. Este hecho causó conmoción en la región: la conducta "tan horrorosa y depravada convence hasta lo infinito de que la principal mira de estos malhechores es la de llevar adelante con la más firme resolución

56 Año 1854 en Libro de Matrimonios, 1749-1880, AHFZ, CAGZ, G, $M N$, exp. 37.

57 Este hombre llevaba más de 10 años en las misiones huicholas. Llegó con el padre Rafael de Jesús Soria en 1842 como secretario de comisario, y en 1853 era comisario de misiones.

${ }^{58}$ Carta de Fr. Becerra, 9 de diciembre de 1853, AHFZ, CAGZ, G, $M N$, núm. 225. 
el exterminio de la raza blanca", ${ }^{59}$ afirmaba un documento militar. Pero en la región, esto no fue objeto de sorpresa. Los pueblos que por décadas habían sido atormentados por este hacendado, como Tenzompa, Nostic, Huejuquilla y Mesquitic, se aliaron rápidamente a los "lozadas" reclamando justicia. Incluso se menciona a un "güichol ladrón de gavilla" que para salvarse dio información al capitán Antonio Suárez con 10 infantes y 10 dragones que eventualmente los condujo al punto en el que se escondían "Lozada y 80 bandidos", que para entonces empiezan a sonar en la documentación militar. ${ }^{60}$ De este enfrentamiento, Lozada quedó herido pero logró escapar hacia San Luis; tres "espías" son aprehendidos, se les levanta su mulada y caballada, se incendian sus abrevaderos y los muertos que "sacan de las barrancas" son colgados, quedando expuestos.

El temor de los levantamientos a favor de Juan Álvarez levanta sospechas por doquier. Los ladrones de Álica empiezan a ser percibidos como "revolucionarios" que aguardan el momento propicio para proclamar la federación. En esta coyuntura, el gobernador de Zacatecas, Francisco G. Pavón, recurre a los franciscanos del Colegio de Guadalupe para solicitar la "cooperación de los Huicholes para la persecución de aquellos bandidos", formando fuerzas de hasta 400 hombres para atravesar la Sierra de Álica. ${ }^{61}$ Y con la agitación detonada con el Plan de Tacubaya, diversos pueblos del séptimo cantón, entre estos los serranos de Jesús María y Huaynamota, se levantan, y el general Parrodi escribe al jefe político de Colotlán para organizar una expedición de "indios güicholes" para "restablecer el orden en Jesús María”, "hallándose estos en la mejor disposición”. ${ }^{62}$

\footnotetext{
59 AHSDN, Operaciones Militares, exp. XI/481.3/6672, f.1v.

60 AHSDN, Operaciones Militares, exp. XI/481.3/5001, f. 81.

${ }^{61}$ AHSDN, Operaciones Militares, exp. XI/481.3/5001, ff. 30 y 91.

62 AHEJ, G-9-858/TEP, "Los antecedentes relativos a la sublevación”, 10 de marzo de 1858.
} 
Hacia finales de la década, la pugna entre liberales y conservadores en esta región estaba lejos de resolverse. Sin embargo, el jefe político de Colotlán tranquilizaba al gobierno del estado

[...] respecto de los pueblos de este canton comprendidos en la Sierra del Nallarit permanecen aun tranquilos mediante las exhortaciones que les ha hecho el personal de esta gefatura, lo mismo que el Sr. Suarez con quien sus autoridades que hemos hecho venir a la Cabecera han comprometido no mesclarse en semejantes crímenes sin que pueda descansarse en tal confianza por la facilidad con que esta clase de gentes faltan a su palabra. ${ }^{63}$

Para los frailes, la coyuntura es menos favorable. Desde 1855 se vuelve sumamente difícil conseguir misioneros para San Andrés, Santa Catarina y Guadalupe de Ocotán y sus sedes quedan la mayor parte del tiempo vacantes. Cuando el padre Vázquez muere en el año 59, el padre Antonio Loera las retoma, pero las abandona al poco tiempo pues son hostilizadas e incendiadas por "motivos de la revolución de Lozada" y se asienta en Bolaños, cuya sede parroquial también había quedado vacante por motivos semejantes. Ese año en que fue expedida, primero la ley de supresión de las órdenes religiosas y después la ley de exclaustración, los franciscanos abandonaron sus misiones y conventos, y reunidos en Guadalupe, Zacatecas, fueron enviados en grupos a la Ciudad de México y a Puebla. ${ }^{64}$ Las misiones serán integradas al obispado de Zacatecas, creado en 1863, y desde entonces las toman a su cargo misioneros diocesanos. ${ }^{65}$

${ }^{63}$ AHEJ, G-15-858 CON/257, Carta del jefe político de Colotlán José de Jesús Borrego, 20 de enero de 1858.

${ }^{64}$ Moreno, "Una historia", p. 330.

${ }^{65}$ AHFZ, Prov. SS Fco. Stgo. Mx, "La evangelización de los huicholes y Guadalupe Ocotán”, Manuscrito de Fr. Alberto Campos, 1979. 


\section{COMO “BUENOS MEXICANOS”: \\ LOS PUEBLOS CORAS EN LA CONFEDERACIÓN MILITAR \\ DE LOS PUEBLOS UNIDOS DEL NAYARIT (1854-1873)}

Entre mayo y junio de 1853, correspondencia entre el comisario de la Mesa del Nayarit, el director político de Sentispac, el jefe político de Tepic, el gobernador del estado de Jalisco y "por recomendación del presidente de la República", se reconoce la "urgente" necesidad de socorrer las misiones coras, atendidas por un solo misionero en Jesús María. Esto debido a

[...] los hechos que pasaron hace poco tiempo entre aquellos indígenas en una insurrección, los resabios de idolatría o creencias supersticiosas que aun parece conservan en su corazón, y [...] el resentimiento que debe afectarles el verse abandonados y desatendidos por tantos años del Gobno, echando [de] menos la protección paternal que el antiguo gobierno colonial les prodigaba. ${ }^{66}$

La misión de Jesús María era la única "viva”, a cargo del franciscano Vicente Buenaventura Cárdenas, quien permaneció por casi 30 años. Siendo uno de sus principales conocedores, las descripciones sobre la vida cotidiana de las misiones con las que contamos para ese periodo son escasas. Fue entonces cuando se organiza la recuperación de las misiones por el curato de Tepic y la visita pastoral del obispo de Guadalajara, Pedro Espinosa Dávalos, acompañado del párroco de Tepic, Ignacio Castro, y de una pequeña comitiva, que atraviesan la sierra desde Atonalisco hasta Jesús María ("el México de la sierra”) y regresan por Huaynamota, hasta Pochotitán. La relación de este viaje de 1854, publicada en el diario El Siglo Diez y Nueve, deja una somera descripción de los coras: viven aislados, son diestros en

66 AHAG, Gobierno, Otras diócesis, Tepic 1849-1850, "Sobre sínodos de los misioneros de Nayarit, 1850”, 21 de junio de 1853. 
el manejo del arco, tienen pocas tierras de labranza privadas de agua, tienen huertas en las riberas, son gente sencilla cuyos vicios han sido exagerados, conocen el "símbolo de la fe" en su propio idioma, bautizan y se casan, y de las ideas que tiene el gobierno, dice "son poco ventajosas". Cual visionario, el padre Castro escribe que, mientras los expedicionarios admiraban la destreza de un niño cora en el manejo del arco y la flecha:

[...] considerábamos con tristeza cuál sería la suerte de Jalisco si una alianza de sangre uniera a los habitantes de la Sierra con esas hordas de bárbaros que devastan los Departamentos de Sonora y de Durango, y de los que solo están separados por la aversión providencial que se tienen las distintas razas indígenas. Pero si los habitantes del Nayarit continúan soportando trabajosamente la vida errante y miserable que pesa sobre ellos, si no se les hacen gustar las dulzuras de la vida social; entonces tarde ó temprano se arrojarán los pueblos comarcanos para vivir del robo y del asesinato $[\ldots] .{ }^{67}$

Fray Buenaventura informa al obispo sobre las tensiones dentro de esta sociedad, "los que son crellentes y los que son mitoteros unos con otros no se quieren". ${ }^{68}$ Es posible que Dionisio Gerónimo, el líder militar cora que destacará dentro de la confederación de los Pueblos Unidos encabezada por Manuel Lozada, perteneciera a los primeros pues escribe el 15 de mayo de 1854 al obispo que, "estando en una necesidad tan grande, como estamos de sacerdote para qe nos de los auxilios divinos y nos ynstruya en la $\mathrm{Fe}$ de Jesuschristo, predicándonos y dirijiendonos en su sana ley" ${ }^{69}$ Con ello se emprendieron las primeras medidas para reactivar las misiones, en las que aún se encuentran "vestigios de los trabajos apostólicos de los antiguos

${ }^{67}$ HDUNAM, Castro, "Visita...", El Siglo Diez y Nueve (21 jun. 1854), p. 2. ${ }^{68}$ Rojas, Los huicholes, pp. 124-126.

69 AHAG, Gobierno, Parroquias, Tepic 1854-1876, Carta de Juan Ignacio López, Miguel Vicario, Dionicio Gerónimo, 15 de mayo de 1854. 
misioneros". La mitra expide salarios para atender tres misioneros de base en Jesús María, La Mesa y Huaynamota, que no provinieron de la Provincia de Santiago de la que eran jurisdicción, sino de la Comisaría de los Colegios Apostólicos que envió franciscanos de Zapopan por falta de personal. ${ }^{70}$ Además, se destinan fondos para establecer escuelas de niñas para fortalecer la transmisión del "símbolo de la fe" de madres a hijas, y se establece un seminario en Tepic para formar jóvenes misioneros en tierra caliente. ${ }^{71}$ Mas estas medidas no habrían de prevenir la violencia que desde ese año repunta en toda la región.

La reacción ante esta nueva etapa de evangelización entre los coras es recibida con menos disposición de colaboración que entre los vecinos huicholes. El coronel Fernando García de la Cadena, conservador de Compostela, informa en 1858 al cura de Tepic que al comisario de las misiones del Nayarit "se lo han llevado preso multitud de indígenas sublevados" en un asalto en Jesús María en que las familias se refugiaron en la iglesia y donde resultaron algunas muertes y "todas estas poblaciones diseminadas en la Sierra han quedado abandonadas". ${ }^{72}$ Otros informes reportan la huida de "familias que pudieron escapar del furor de los indios" y migran "en la mayor miseria" hacia Mesquitic y Huejuquilla. ${ }^{73}$ Todos los pueblos del Nayar, dice el comisario municipal de San Juan Peyotán, se declaran a favor "del malvado Lozada". Pero desde el cantón, y por instrucción de Carlos Rivas, quien se nombra "Apoderado General de los

70 Según nota 72 al pie de página de Martínez, Introducción a "Diario", p. 459.

71 AHAG, Gobierno, Parroquias, Tepic 1854-1876. Notas sueltas del 18 de abril de 1856.

${ }^{72}$ Cartas de fechas posteriores constatan que al comisario Cárdenas lo dejan después libre y sigue ejerciendo funciones en Jesús María, AHAG, Gobierno, Parroquias, Otras diócesis, Tepic 1858, Carta de Secundino Pérez, 4 de febrero de 1858.

73 AHEJ, G-15-858 CON/257, Carta de Narciso Gutiérrez, 16 de enero de 1858, y Carta de José de Jesús Borrego, 20 de enero de 1858. 
Indígenas", Manuel Lozada es comisionado para visitar Huaynamota, donde se entrevista con representantes de los pueblos de Huaynamota, Jesús María, San Francisco, San Juan Peyotán y Mesa del Nayarit. En su informe, Lozada escribe las resoluciones del encuentro:

Y les he impuesto las condiciones acostumbradas de arreglos y han convenido a estar pacíficos, y volver al orden y bajar las familias a sus pueblos, y no andar causando mas desordenes, solo esperar el resultado del Supremo Gobierno, y les he dicho que dejen volver a los vecinos a frosear [?] sus propiedades, y han respondido que no, que la cuestión ha sido por ellos, y les he impuesto que les debuelban lo que les hayan tomado a los mismos vecinos, como son de intereses de muebles y otras cosas que les hayan tomado de sus casas, y me han dicho que no entregan nada, porque mas les han tomado ellos a los pueblos. ${ }^{74}$

Los firmantes declaran además desconocer la villa de Santiago como cabecera y a toda fuerza que provenga de ese camino, pues solo reconocerán a Tepic y lo que llegue por el camino de San Luis. El año parteaguas será 1858. Declarado el Plan de Tacubaya, Manuel Lozada y Carlos Rivas organizan los contingentes desde la sierra, los valles y las tierras bajas que conforman las fuerzas del ejército conservador en el séptimo cantón, financiadas por una serie de familias organizadas en torno a los intereses comerciales de la casa Barrón y Forbes de Tepic. Ese mismo año, Lozada es nombrado dirigente de los Pueblos Unidos del Nayarit.

Es así como se desata la guerra que progresivamente va envolviendo a los pueblos del Nayar, según motivaciones diversas, y que ya trastornaba distintas regiones del territorio nacional. La sierra entre Huejuquilla y Huaynamota se vuelve zona

${ }^{74}$ AHEJ, G-9-858/TEP, Informe de Manuel Lozada, 4 de marzo de 1858. 
disputada por los líderes locales que hicieron suya la pugna entre liberales y conservadores que polarizaba al país y obligaba a las poblaciones rurales a tomar partido. En el bando liberal, los jefes Remigio Landa y Rafael Madera aparecen como los jefes influyentes en la sierra en el contexto de los conflictos de terrenos; destacan por mal comportamiento y abusos hasta ser capturados y ejecutados. ${ }^{75}$ En el bando conservador, Rivas y Lozada disputan el control sobre esta región entre 1858 y 1861 con una fuerza de 500 hombres, entre ellos coras de Jesús María, San Lucas, otros de Chimaltitán y Bolaños, "rancheros e indios mal armados de lanzas y garrotes y algunos güicholes con flechas". ${ }^{76}$ En un bando público, Rivas comunica que "el objeto de venir al distrito de Colotlán es establecer el gobierno emanado del plan de Tacuballa y reformado en la Ciudad de Méjico en diciembre de $1857 "{ }^{77} \mathrm{El}$ apoyo al movimiento conservador incluye a algunos clérigos de la región, como el cura y juez eclesiástico de Bolaños, José María Rentería, que en 1860 almacenaba armas y municiones y convencían a parroquianos de Huilacatitan de unirse al mando de Bonifacio Almeida hasta que huye a Guadalajara tras ser asaltado por una "gavilla de ladrones y asesinos con carácter político". ${ }^{78}$ Del lado de Huejuquilla, el padre Emeterio Castro es relevado del cargo en 1861 por su involucramiento, y el padre Godines se alía con el lozadista Marco Flores. ${ }^{79}$

Cuando los liberales retoman la Ciudad de México, desde Guadalajara se aprovecha la coyuntura para recuperar el control en la región. El gobernador de Jalisco, Pedro Ogazón, organiza una campaña militar entre el mes de diciembre de 1861 y enero

\footnotetext{
75 Brittsan, Popular Politics, pp. 106-107.

76 Meyer, La tierra de Manuel Lozada, p. 169.

77 HDUNAM, El País (1a ago. 1861), p. 2.

78 AHAG, Gobierno, Parroquias, Bolaños 1850-1859, Carta de José María Rentería, 4 de abril de 1859.

79 Citados en BritTsan, Popular Politics, pp. 107 y 42 respectivamente.
} 
de 1862 que atraviesa el territorio cora con 5000 hombres. El 11 de enero regresa a Tepic pues "como los indios andan de cerro en cerro no pudieron dar golpe decisivo" y deja al mando a Ramón Corona y Antonio Rojas, dos militares liberales clave en el curso del conflicto en la región. ${ }^{80}$ Con el desembarco de las tropas europeas en Veracruz, el eje del conflicto regional adoptaría una nueva escala. Para 1863, las fuerzas conservadoras de Jalisco se organizan al mando de los generales Manuel Lozada, Carlos Rivas y Fernando García de la Cadena, que mantienen el control sobre más de 600 leguas cuadradas del séptimo y octavo cantón, y del general Remigio Tovar en el décimo cantón. Como zona de refugio, de retaguardia y de la guerra de guerrillas, los enfrentamientos alcanzan los pueblos coras de la Sierra. Santa Teresa es atacado por las fuerzas liberales del batallón "Pueblos Unidos" -formado por indígenas de la región de Huajicori (cerca de Acaponeta) que medio siglo antes eran hablantes de cora y mexicano-, un batallón decisivo en las campañas militares en la sierra. ${ }^{81}$

La escalada de violencia debió influir en la adhesión formal de soldados coras a los cuadros militares del séptimo cantón. Primero, como parte de "los Pueblos Unidos", luego integrados a las tropas auxiliares del ejército conservador, bajo el mando directo de Manuel Lozada, general de la División de Álica, y después como parte de las tropas auxiliares imperiales de Maximiliano de Habsburgo. Durante la alianza con los imperialistas, el territorio controlado es reconocido con el epónimo cora como Departamento de Nayarit, gozando además de un salario quinquenal y con licencias temporales durante el periodo de siembra y cosecha. ${ }^{82}$

\footnotetext{
80 HDUNAM, El País (21 ene. 1862, 1 y 6 feb. 1862).

81 PeÑa Navarro, Estudio histórico, pp. 163-165.

82 Entre abril de 1864 y marzo de 1866, en MeYer, Manuel Lozada, p. 241; Peña Navarro, Estudio histórico, p. 166. El nombre de "Nayarit" no será recuperado sino hasta la erección del estado constitucional en 1917.
} 
La participación dentro de este cuerpo militar les implica sujetarse a la organización que en esos años se consolida y que se sujeta en lo militar al cuartel general en San Luis de Lozada y en lo político a la jefatura política en Tepic. Los pueblos coras formaron parte del distrito militar de Huaynamota, que establece un consejo encargado de la vigilancia y de las diligencias en caso de delitos, que primero informa al cuartel general y, en caso condenatorio, al juez ordinario que determina la sentencia conforme a las leyes comunes. Y dentro de este distrito, a dos comandancias, la de Mesa del Nayarit y la de Jesús María. En cada comandancia se establece un consejo compuesto de un comandante militar que ejerce como presidente y dos oficiales subalternos de la clase de capitanes que fungen de vocales secretarios. Como lo explica Jean Meyer, cada pueblo suministra su contingente: tiene una lista de hombres en edad y condición física para combatir, el 10\% está siempre en armas, según un sistema de rotación que asegura una movilización mínima y permanente y la familiaridad de todo el contingente con las prácticas milicianas, también se encarga de su alimentación y están armados con lanza, sable, machete, puñal, pistola y fusil. ${ }^{83}$

Si bien no tenemos perfectamente documentada la evolución de esta organización militar en la sierra cora, sabemos que Dionisio Gerónimo fue ascendiendo en la jerarquía militar, de comandante de batallón hasta el grado de coronel, lo que debió modificar el papel de la Mesa del Nayarit respecto a la organización de los contingentes serranos a la que también se incorporaron algunos huicholes. Asimismo debió jugar un papel decisivo en el arreglo con los franciscanos que llegan a las misiones. Por ejemplo, fray Buenaventura Méndez, encargado de la misión de Huaynamota, a la que llega en 1858, escribe con alegría a Tepic en 1864 solicitando licencia para pedir limosnas

83 MeYer, Manuel Lozada, pp. 240-241, 251-254; El Amigo del Orden Nacional (11 sep. 1862), pp. 1-2. 
a fin de edificar una iglesia con bóveda en San Juan Peyotán y otra en Huaynamota:

[...] gracias a Dios Ntro Sr que a llenado de sentimientos nobles y caridad el corazón del Exmo. Sr. Gral. D. Manuel Lozada. He hablado detenidamente con el acerca de esto mismo y me a dicho que me proporcionara todos los recursos que pueda, y que será un influjo principal en todos los puntos que están bajo de su digno mando para que consiga con mas facilidad alguna suma considerable para dar santo fin con esta puerta tan amplia que se me ha abierto, Exmo $\mathrm{Sr}$, mi corazón se a llenado de un juvilo indecible, $\mathrm{y}$ animado mas mi espíritu para seguir mi intento. ${ }^{84}$

A pesar de la evacuación de las tropas francesas y la exclaustración definitiva decretada en 1867, la autonomía de facto lograda por las fuerzas de los Pueblos Unidos da protección a los franciscanos en la sierra cora a lo largo de la década de $1870 .{ }^{85}$

Gracias a los planes, circulares y manifiestos hechos públicos, conocemos parte de los procesos organizativos colectivos detonados. ${ }^{86}$ Por ejemplo, en el mes de enero entre 1870 y 1873, tuvo lugar la "Asamblea de los Pueblos", que previo a su celebración convocaba a que en cada pueblo se reunieran los domingos todos sus habitantes y autoridades militares para "examinar y discutir detenidamente" los asuntos sometidos a deliberación y tomar resoluciones. ${ }^{87}$ El movimiento se expandió y se contrajo durante su existencia, pero en su trayecto de

${ }^{84}$ AHAG, Gobierno, Parroquias, Tepic 1854-1876, Carta de Fr. Buenaventura Méndez, 23 de noviembre de 1865.

85 AHAG, Gobierno, Otras diócesis, "Misiones del Nayarit que ahora son vicaría del curato de Tepic, $1879 "$.

86 Esta documentación puede consultarse en Meyer, La tierra de Manuel Lozada; Aldana Rendón, La rebelión, pp. 181-209; PeÑa Navarro, Estudio histórico, pp. 250-254.

87 Convocatoria en Meyer, La tierra de Manuel Lozada, pp. 287-294. 
vida la lealtad de los pueblos coras de la Mesa del Nayarit "y su comprensión”, de Jesús María, San Juan Peyotán, San Lucas, y del pueblo tecual-mexicanero de Huaynamota es remarcable. Estos firman las actas de la Asamblea de los Pueblos, la proclama titulada "Los pueblos del Estado de Nayarit, a la raza indígena y demás individuos que constituyen la clase menesterosa del pueblo mejicano" que se hizo pública con otras 70 localidades firmantes, y también el "Plan libertador proclamado en la Sierra de Álica por los pueblos unidos del Nayarit" del 17 de enero de 1873 con 55 localidades firmantes. Esta constancia no se constata en los demás pueblos indígenas del Nayar. Por ejemplo, Santa Teresa no firma la proclama de 1870 y es de los primeros en pactar con los liberales en 1873. A pesar de participar en acciones militares, los pueblos tepecanos como Azqueltán y Acaspulco, los tepehuanes de Santa María Ocotán y San Francisco y el pueblo huichol de Guadalupe Ocotán no firman ninguno de estos documentos que legitiman al movimiento. ${ }^{88}$ También es importante señalar que ningún pueblo cora forma parte de las comisiones de deslinde y reconocimiento de terrenos que al momento mantienen litigios con haciendas, a las que la mitad de los pueblos adheridos se incorporan con representantes. Esto puede ser indicativo de la recuperación de sus territorios de las manos de los vecinos desde los sucesos de 1858.

Con la proclama del Plan Libertador que anuncia una nueva campaña militar en 1873, tras casi cinco años de paz relativa, Dionisio Gerónimo, ya como coronel, dirige el batallón que

${ }^{88}$ Meyer, "El ocaso de Lozada", p. 565. En este artículo fundador de una serie de trabajos sobre el lozadismo, Meyer afirma que Lozada "tuvo bajo su dirección (siempre directiva, jamás imperativa) a los tepehuanes de Santa María Ocotán, San Francisco y Quiviquinta, a los de Santiago Teneraca y a los de Tasquaringa, a los huicholes que se distribuyeron entre los cuatro pueblos situados a lo largo del río Chapalagana (San Andrés y Santa Catarina andan peleados por un problema de límites), a los coras de...”. Desgraciadamente no nos proporciona sus referencias. 
pretendía tomar la ciudad de Zacatecas. Al parecer, su fuerza regresa a la sierra cuando le llega la noticia del repliegue del destacamento de Lozada en las afueras de Guadalajara durante la Batalla de la Mohonera los días 28 y 29 de enero. Esta batalla justificó una agresiva campaña militar de las fuerzas de gobierno con 10000 soldados dirigida por tres secciones que penetraron la Sierra de Nayarit por rumbos distintos. El comandante Fuero dejó constancia de la cooperación de autoridades y jefes militares huicholes que le prestaron sus servicios "que en efecto me fueron muy útiles" ${ }^{89}$ Progresivamente los comandantes lozadistas fueron pactando el indulto y las condiciones de su rendición. En abril se reunieron los comandantes en Huaynamota, ratificaron su pacto de unión y el estado de guerra, en un documento firmado por los "pueblos unidos de la Mesa del Nayarit". Pero a los pocos días, el batallón liberal también nombrado "Pueblos Unidos" atacó la Mesa del Nayarit bajo el mando del exjefe lozadista, Agatón Martínez.

Dionisio Gerónimo firmó su acta de sumisión y de los demás comandantes bajo su mando en el rancho de la Cofradía, el 24 de abril de 1873:

Guadalupe Hernández, representante del C. Coronel Dionisio Gerónimo, Comandantes Nicolás López, Carpio Serrano, Ignacio Vázquez y Luciano Molina, Juez Comisario Manuel Medina y principales Valentín Estrada e Ignacio Rodríguez, en representación de todos los habitantes de la Mesa del Nayarit, y ante el C. Gral Franco. Tolentino, protestamos someternos a la obediencia del Supmo. Gobno. ofreciendo como mejor convenga en este solemne compromiso. Por demás nos parece expresar que esperamos las garantías que el Gobno. nacional da a todos los buenos mexicanos. Para que conste debidamente firmamos con el espresado Sr. General. ${ }^{90}$

89 Rojas, Los huicholes, p.191.

90 Peña Navarro, Estudio histórico, pp. 311-313. 
Durante esta campaña militar, los primeros pueblos en segregarse del mando militar de Dionisio Gerónimo fueron "San Blas, San Buenaventura, Saicota, Milpillas, Picachos y Santa Teresa", la mayoría coras. Y una vez concluida la campaña militar e integrado a las tropas auxiliares liberales de Tepic, Gerónimo expide circulares a los pueblos huicholes "bajo su mando" así como al pueblo de Huaynamota, que se mantiene rebelde, pero dejan de responder, neutralizando su autoridad. El gobierno del estado restringe su autoridad militar en una serie de escritos de 1874 , "por pretender seguir gobernando como en tiempo de Lozada”, y expide circulares a los pueblos de Huejuquilla, Soledad, Tenzompa, Santa Catarina, San Andrés Cohamiata, entre otros, para que se sujeten a la autoridad del gobierno del estado "previniendo igualmente a las autoridades de Jesús María y de la Mesa cesen en la intervención que han ejercido sobre todos los pueblos que dejo citados". ${ }^{1}$

DISPOSITIVOS POLÍTICOS INDÍGENAS, MÁS ALLÁ DE LA COYUNTURA Y LA (RE)ORGANIZACIÓN DE LAS RELACIONES DE PODER DESPUÉS DE LA GUERRA

Falta aún por entender la diversidad de posicionamientos políticos de los pueblos indígenas del Nayar, que no se agota con los pueblos coras y huicholes abordados, pues el batallón liberal "Pueblos Unidos", formado por indígenas de la región de Huajicori-Acaponeta que se mantiene "fiel a la República",92 los pueblos tepecanos en torno a Azqueltán, aniquilados al final de la guerra, o el caso particular del pueblo Huaynamota, hablante de náhuatl, el primero en adherirse a la causa lozadista y el último en abandonarla, han sido poco investigados. Si bien hay que ser cautelosos a la hora de proponer cualquier generalización

91 Todas las citas de 1874, AHEJ, G-5-873 CON/1173, exp. 1-6.

92 PeÑa Navarro, Estudio histórico, p. 172. 
que reifique lo indígena como entidad homogénea y esencialista, nos hemos centrado en las experiencias "cora" y "huichola", no solo por estar mejor documentadas, sino para poner a prueba el potencial analítico de la comparación, que no solo busca destacar semejanzas -ambos sostienen más de una alianza en el curso de los años de guerra-y diferencias -sus posicionamientos políticos dentro de la trama regional-nacional lozadistas-conservadores/ liberales-sino repensar sobre sus dispositivos políticos con perspectiva histórica. El objetivo ha sido abordarlos de manera conjunta, pues solo así se vuelven inteligibles los modos en que coras y huicholes alternan entre la colaboración y el antagonismo, en función de las condiciones externas que los amenazan, revelando una dinámica política particular en defensa de la autonomía territorial y político-religiosa de los pueblos del Nayar en su conjunto, configurando política y territorialmente a toda una región. Volvamos sobre la coyuntura para entonces reflexionar sobre los efectos de la guerra en estas sociedades.

En el caso de los pueblos huicholes, y con base en la documentación con la que contamos hasta ahora, podemos hacer algunas inferencias. Su participación en el lozadismo nunca fue ni constante ni oficial, como tampoco se ha identificado ningún liderazgo militar. Sin embargo los datos parciales indican que por lo menos "algunos huicholes" formaron parte de las gavillas de la región, de las fuerzas conservadoras que al mando del general Carlos Rivas controlaron la región Huejuquilla-Bolaños en la década de 1860, y que para 1873 pueblos huicholes estaban bajo el mando militar de Dionisio Gerónimo. Si en el periodo colonial la lealtad de los pueblos huicholes era cuestionada por las autoridades coloniales por ser "mui afectos a los nayaritas", la colaboración con los pueblos coras vecinos para este periodo se sostiene, como también se constata la continuidad de las relaciones rituales entre ambos, en particular la entrega de ofrendas a la cueva en la Mesa del Nayarit, lugar de culto a Tzacaimuta, considerado el sol de occidente en el lenguaje de la mitología 
huichola. Esta colaboración debió justificar que al final de la guerra, familias huicholas migraran a establecerse en los márgenes del río Santiago, en las inmediaciones de San Luis de Lozada, en Agua Caliente y en San Juan Peyotán. ${ }^{93}$ Su colaboración como milicianos en las fuerzas liberales cantonales y del estado en contra de los rebeldes coras y demás lozadistas llevaban al prefecto de Colotlán a describirlos como "pobladores pacíficos que, no obstante su contacto con la sierra del Nayarit, jamás se han revelado contra las autoridades del estado". ${ }^{94}$

A pesar de los problemas agrarios que afectaban a los tres pueblos que pudieron haberlos arrojado en masa a "los lozadas”, se optó por la mediación y colaboración con eclesiásticos, militares y funcionarios de gobierno con un fin muy específico: la defensa de sus costumbres y de sus terrenos. Lo que a primera vista podría leerse como una falta de constancia, resulta verdaderamente consecuente visto desde la larga duración, pues el establecimiento de alianzas plurales y simultáneas ha sido un comportamiento político que ha demostrado su eficacia a lo largo de la historia. ${ }^{95} \mathrm{La}$ autonomía de cada pueblo para el establecimiento de sus respectivas alianzas alterna con coyunturas que hacen posible la acción conjunta, más allá del pueblo o grupo étnico, sin que esto implique naturalizar esta "unidad" en el plano político y territorial. ${ }^{96}$ Dicho en términos huicholes, se puede hacer la Fiesta del Peyote y ser un buen cristiano.

${ }^{33}$ AHAG, Gobierno, Otras diócesis, Tepic 1862-1877, Carta firmada por vecinos del pueblo de San Luis, 30 de abril de 1878; y en 1884 según Estragues en López, Algunos documentos, pp. 75 y 96. En mi revisión de las fuentes tempranas del siglo XIX no encontré presencia huichola documentada en esta parte occidental de la sierra.

94 Cita de 1885, en Meyer, Manuel Lozada, p. 198.

${ }^{95}$ Sobre las alianzas plurales como estrategia política exitosa entre los huicholes desde una perspectiva histórica véase LiRA, "Una lectura de la defensa". ${ }_{96}$ Este aspecto también ha sido subrayado recientemente por McArdLE, In the Lands, y cuestionado por PANTOJA, La guerra indigena, pp. 127-130. 
Esta tenacidad, aunque reprobada por los franciscanos, no fue del todo mal comprendida por estos al vislumbrar la relación intrínseca entre "terrenos, idolatrías y gobierno". Buscaron defender el territorio con los medios a su disposición sentando las bases de confianza para combatir las idolatrías y asumir el control para la designación de las autoridades, mermando la forma de organización nativa. No obstante, sus adelantos no surtieron el efecto deseado y en 1884 el padre fray José María Estragues redacta su "Lamentable reseña de la tribu huichol" para alertar que "los Huicholes propenden al estado de 'naturae purae' y quieren retroceder al estado del gentil y del salvaje”. Como remedio propuso una nueva estrategia: "que para cosechar de algún especial grano, es forzoso sembrar semilla de la misma especie", es decir: "sacar de entre ellas mismas [las tribus] sus sacerdotes que los evangelizaran". ${ }^{97}$

La puesta en práctica de esta nueva estrategia la corroboró Carl Lumholtz en su paso por los pueblos huicholes en 1894, al relatar que, en una visita pastoral de 1879, el obispo de Zacatecas tomó a su cargo la educación de nueve niños huicholes para instruirlos en la profesión sacerdotal. Uno de ellos era maestro de escuela en el pueblo cora de Jesús María en 1894, al que las autoridades coras "consideraban con justicia, preferible al común de los maestros mexicanos". ${ }^{98} \mathrm{Y}$ en su paso por San Andrés, describe los tres ramos de las "autoridades nativas" en "fuerza plena", pero el gobernador de San Andrés carecía de legitimidad pues había sido impuesto por el jefe político de Mezquitic, “y los viejos no lo quieren". ${ }^{99}$ Es decir, que el debilitamiento de la estructura de poder nativa iniciada por los franciscanos creó las condiciones para la implementación del nuevo sistema municipal bajo la política porfirista que, además, condujo al eventual

97 Estragues, en López, Algunos documentos, pp. 111-113.

98 Lumholtz, El México desconocido, p. 496.

99 AMNH, DAA, “Diary, 1898”, de Carl Lumholtz, p. 16. 
despojo territorial y a una tercera etapa de evangelización liderada por los padres josefinos, entre estos el padre Marciano Ríos, cora de nacimiento.

En el caso de los pueblos coras, su participación en las "fuerzas de los pueblos unidos del Nayarit" es ampliamente corroborada. Esta sentó las condiciones para retirar a los vecinos sus terrenos y negociar los términos del regreso de los franciscanos a la región, que a fin de cuentas resultaron ser mejores aliados que los jesuitas y que los sacerdotes seculares. Y ello se constata cuando, en 1884, una comisión compuesta por varios “indígenas naturales" de la Mesa del Nayarit escribió un pliego al obispo imponiendo tratar con los franciscanos, que según el sacerdote autor de un informe "les han tolerado muchas prácticas que es preciso desarraigar poco a poco". Este añade al informe una larga lista de quejas: se rehúsan a pagar obvenciones, ejecutan “danzas estrepitosas semicómicas [...] en los templos", los "mayordomos y priostes [asisten] en presbiterio desnudos totalmente [...] y esto no por pobresa", se niegan a ser confesados antes de morir y "todos quieren sepultados en el templo"; en fin, que ellos guardan la llave del templo y "se consideran dueños absolutos". 100

La recuperación de su autonomía durante los 20 años de confederación de los pueblos unidos creó las condiciones para rescatar de los espacios de culto, que en palabras del antropólogo Philip Coyle implicó un proceso de formulación que combinó en una sola tradición el mitote cora practicado por los grupos parentales antes clandestinos y el ceremonialismo derivado del catolicismo que sirve de fundamento a los pueblos política y religiosamente autónomos y soberanos. ${ }^{101} \mathrm{El}$ padre Estragues

100 AHAG, Gobierno, Otras diócesis, "Misiones del Nayarit que ahora son vicaría del curato de Tepic, 1879”, Carta de Manuel María Estragues”, sin fecha legible.

101 Con base en su estudio en Santa Teresa, Coyle, Náyari History, p. 94; Jáuregui, "Del reino de Lozada", p. 37. 
se conmocionaba al describir la Semana Santa practicada por los coras de Jesús María en 1884:

Más lo que mas repugna a la moral, son ciertas acciones obcenas que estos infelices en medio de su desnudez observan en lugares públicos, sin otro disfraz ni máscara que el tiznarse todo el cuerpo. Terminan todas estas y otras ceremonias el Domingo de Pascua con la inaudita ceremonia de bañar a todas las imágenes en el río revueltas con la gente. Es una práctica muy antigua de este pueblo, y sin que el infraescrito haya podido averiguar su significado. ${ }^{102}$

En este sentido, el papel de la Mesa del Nayarit, desde donde Dionisio Gerónimo ejerce su liderazgo militar, se revitaliza como "instrumento de cohesión” y cabecera militar y ritual de los contingentes más allá de los coras. Esta posición de jerarquía debió ser legitimada por los demás pueblos que mantienen relaciones rituales con este sitio -como los huicholes-, y funge como la red a través de la cual Gerónimo extiende su esfera de influencia, adhiriendo a los pueblos serranos en el sistema de defensas en el curso de la guerra. Este sitio de culto dedicado a los antiguos gobernantes, activo también entre los coras, fue documentado en 1884 por fray Estragues:

Debido a la ausencia del sacerdote, y en argumento más bien de la ignorancia en que esta gente vive, se sabe que estos guardan en cierta cueva que existe en la proximidad del vecindario, algunos cadáveres que se supone sean de los pro-héroes fenecidos de la misma tribu, y a los que rinden culto y ciertos homenajes ejecutados por el más anciano y hábil, quien además, es el que convoca a los otros a las asambleas mitológicas. En tiempos de alguna calamidad, suelen reunirse los ancianos en el lugar citado y pasan allí hasta cinco días y

102 Estragues en López, Algunos documentos, p. 103. 
cinco noches sin hablar, dormir, comer ni beber. En cuyo caso, tiene el principal la prerrogativa de adivinar, según ellos, lo futuro. ${ }^{103}$

Visto con perspectiva histórica, vale reconsiderar para este periodo la propuesta de Raquel Güereca en su estudio sobre la conquista cora de 1722, de entender el poder político-ritual ejercido desde la Mesa del Nayarit en términos de un estado de tipo segmentario, que tiene su antecedente arqueológico para la región transtarasca propuesto por Phil Weigand. Desde la perspectiva estructural desarrollada por la antropología política, este modelo permite repensar las dinámicas de antagonismo y de colaboración entre coras y huicholes, que hacen posible que la autonomía a nivel de grupos locales se interrumpa cuando la acción colectiva es concertada en contra de agentes externos, así como el que esta confederación no sea permanente pues la unión política no es el estado normal de las cosas. ${ }^{104}$ Los comportamientos políticos corroborados en la larga duración, como los procesos de expansión política y militar entre los coras, así como las formas de expansión territorial características de los huicholes, habilitadas por las redes rituales estudiadas por Paul Liffman, ${ }^{105}$ cobran nuevos sentidos que debemos seguir explorando.

Este tipo de organización y sus "prácticas segmentarias” han sido retomadas en otros contextos, por ejemplo, en los pueblos indígenas de la Pampa y la Patagonia argentinas en el siglo XIX estudiados por Ingrid de Jong, para explicar la capacidad de ciertos pueblos para evitar la concentración de poder. Este estudio

103 Estragues en López, Algunos documentos, p. 87.

104 SAHLins, “The Segmentary Lineage”, p. 326.

105 Esto confirma la propuesta de Paul Liffman sobre el modo en que las prácticas religiosas (que involucra intercambios de tipo comercial y ceremonial) son la base para extender demandas territoriales en las arenas nacionales e internacionales contemporáneas, conformando un sentido de territorialidad que incluye territorios más allá de los reconocidos por el estado mexicano, como el caso de la Laguna de Chapala, desarrollado a profundidad en LiffMAn, "The Historia of Islands", pp. 177-195. 
también ha demostrado que la negociación de funcionarios de gobierno con "caciques principales" indígenas al mismo tiempo que los reconoce como autoridades legítimas, altera o afecta otras formas de organización indígena al incorporar a estos caciques a la verticalidad del poder militar. ${ }^{106} \mathrm{Un}$ proceso semejante observamos en la relación entre el liderazgo ejercido por Dionisio Gerónimo, su prolongación más allá de la coyuntura de la guerra, y los nuevos espacios de poder aprovechados por antiguos combatiente lozadeños durante el porfiriato. ${ }^{107} \mathrm{Sin}$ embargo, la restricción de su participación en la política regional restringe a su vez su condición de ciudadanos, sujetándolos a la jefatura política de Tepic "por no estar todavía la mayor parte de aquellos habitantes en aptitud para ejercer el derecho del sufragio público y porque no hay allí el número suficiente de individuos capaces para desempeñar los cargos del Municipio". ${ }^{108}$

Estos aspectos ponen de relieve la potencia analítica de la comparación entre trayectorias históricas particulares e invitan a afrontar el problema de la escasez de fuentes al poner a prueba modelos interpretativos que nos lleven a reflexionar sobre las organizaciones políticas indígenas modernas, sus cambios y mecanismos de adaptación, y modos de interacción con el aparato del Estado. Podemos concluir con algunas de las consecuencias de la guerra en el corto plazo: desterrados, ejecutados, colgados, epidemias, hambrunas, migraciones, pueblos arrasados, exclusión del sufragio universal. En el largo plazo, el análisis ha resultado más complejo. En el caso de los huicholes, la ausencia

106 De Jong, "Prácticas estatales”, p. 167.

107 En 1884, las autoridades gubernamentales en el pueblo de Jesús María son representadas por dos jueces, un sínodo y tres transitorios; de estas autoridades reconocemos a un lozadista, José María Candelario, firmante del Acta de Asamblea de 1870.

108 En 1888, Pérez González, Ensayo, pp. 12-13. En 1910 también se niega erigirla en partido. Será hasta 1939 cuando se erige el municipio de La Yesca, en GuTIÉRrez, El territorio, p. 102. 
de liderazgos pareciera a primera vista un indicio de su capacidad para evadir la verticalidad del poder que se asocia a su organización descentralizada y la autonomía de cada pueblo. Sin embargo, la segunda etapa evangelizadora demostró de manera eficiente dar inicio a un proceso que quebranta las formas de organización locales y crea nuevos problemas surgidos de la indefinición de linderos entre Tepic y Jalisco, ${ }^{109}$ mismo que es repuntado con la política porfirista, y la entrada de compañías deslindadoras, lo que será la tercera etapa evangelizadora con la llegada de los misioneros josefinos en los albores del siglo xx. En el caso de los coras, destaca la capacidad de movilización y de acción colectiva más allá de la etnia y la clase, fortaleciéndose la figura del líder militar que media en dichas alianzas y que hemos mostrado tiene precedentes históricos. Esta mediación dota a esta figura de una influencia que impacta a las otras ramas del poder político y religioso local, al incorporar estos ramos a la verticalidad del poder y habilitar formas de concentración de poder que serán perpetuadas en las décadas posteriores. ${ }^{110}$ Mas sabemos que la verticalidad del poder como uno de los efectos de la guerra prolongada no logra cimentarse pues las comunidades serranas rehabilitan la organización y el territorio colectivo por la vía legal décadas más tarde. Esta experiencia

109 Después del fusilamiento de Lozada, S. Lerdo de Tejada dicta que los pueblos que antes pertenecían al octavo cantón regresen a su autoridad política. Pero esta disposición no se aplicó a las poblaciones de La Yesca y Camotlán, que hasta hoy mantienen disputas en los límites estatales. Esta ambigüedad de los límites estatales abonó a que algunos personajes asentaran su poder en la región formando cacicazgos opresivos y violentos. TÉlLEz, "Territorio", pp. 140-151.

110 Este proceso nos permite explicar mejor por qué durante la Revolución tanto coras como huicholes no escaparon al surgimiento de figuras caciquiles que llegaron a concentrar un poder sin precedentes, otorgando legitimidad al naciente estado revolucionario, estudiado por MoRRIs, “The World Created Anew'", y también por TÉLLEZ ya mencionado, y Weigand "El papel de los indios", pp. 121-130. 
histórica, actualizada y transmitida en las prácticas rituales de los huicholes contemporáneos, advierte sobre el peligro que habilitan las formas concentradas de poder, por lo que las estructuras jerárquicas son revertidas cíclicamente y las imágenes de la totalidad que colectivamente se crean deben diluirse, manifestándose solo de manera efímera. ${ }^{111}$

\section{SIGLAS Y REFERENCIAS}

AGN Archivo General de la Nación, Ciudad de México, México.

AHAG Archivo Histórico de la Arquidiócesis de Guadalajara, Jalisco, México.

AHEJ Archivo Histórico del Estado de Jalisco, México.

AHFZ, CAGZ, G, MN Archivo Histórico Franciscano de Zapopan, Colegio Apostólico de Guadalupe Zacatecas, Gobierno, Misiones del Nayar, Jalisco, México.

AHFZ, Prov. SS Fco. Stgo. Mx. Archivo Histórico Franciscano de Zapopan, Provincia de los Santos Francisco y Santiago, Jalisco, México.

AHSDN Archivo Histórico de la Secretaría de la Defensa Nacional, Ciudad de México, México.

AMNH, DAA American Museum of Natural History, Division of Antropology Archive, Nueva York, Estados Unidos.

HDUNAM Hemeroteca Digital de la Universidad Nacional Autónoma de México, Ciudad de México, México.

Aldana Rendón, Mario A., La rebelión agraria de Manuel Lozada, 1873, México, Fondo de Cultura Económica, 1983.

Arias y SaAvedra, Antonio, "Información rendida en el siglo xviI por el P. Antonio Arias y Saavedra, acerca del estado de la Sierra de Nayarit y sobre culto idolátrico, gobierno y costumbres primitivas", en CALVO, 1990, pp. 284-309.

Arlegui, José, Crónica de N.S.P.S. de Zacatecas, México, Cumplido, 1851.

BOLETÍN DEL AGN, “Las tropas de indios flecheros en Nueva España en 1792", en Boletín del Archivo General de la Nación, Primera Serie, Ix: 4 (oct.-dic. 1938) pp. 731-767.

111 Argumento desarrollado en LiRA, "Nuestra Madre Milpa Joven”. 
BritTsan, Zachary, Popular Politics and Rebellion in Mexico: Manuel Lozada and La Reforma, 1855-1876, Nashville, Vanderbilt University Press, 2015.

Calvo, Thomas, Los albores de un nuevo mundo: siglos XVI y XVII, México, Universidad de Guadalajara, Centro de Estudios Mexicanos y Centroamericanos, 1990.

Calvo, Thomas y Jesús Jáuregui, “Prólogo”, a Ortega, 1996, pp. vii-li.

Castro Gutiérrez, Felipe, “La rebelión del Indio Mariano”, en Estudios de Historia Novohispana, vol. 10, 1991, http://www.ejournal.unam.mx/ehn/ ehn10/EHN01014.pdf

Castro Gutiérrez, Felipe, Virginia Guedea y José Luis Mirafuentes GaLván (eds.), Organización y liderazgo en los movimientos populares novohispanos, México, Universidad Nacional Autónoma de México, 1992.

Coyle, Philip E., Náyari History, Politics, and Violence. From Flowers to Ash, Tucson, University of Arizona Press, 2001.

Daneels, Annick y Gerardo Gutiérrez Mendoza (coords.), El poder compartido. Ensayos sobre la arqueología de las organizaciones políticas segmentarias y oligárquicas, México, Centro de Investigaciones y Estudios Superiores en Antropología Social, El Colegio de Michoacán, 2012.

De Jong, Ingrid, "Prácticas estatales sobre una sociedad segmental: la subordinación de los indios amigos en Azul y Tapalqué”, en Revista Trefos, 12: 2 (2014), pp. 155-189.

Guardino, Peter, Campesinos y política en la formación del Estado nacional en México: Guerrero 1800-1857, México, Gobierno del Estado de Guerrero, 2001.

Güereca, Raquel, "Las milicias de indios flecheros en la Nueva España, siglos XVI-XvII", tesis de maestría en historia, México, Universidad Nacional Autónoma de México, 2013.

GÜERECA, Raquel, "Caciques, lenguas y soldados fronterizos: actores indígenas en la conquista del Nayar (1721-1722)", tesis de doctorado en estudios mesoamericanos, México, Universidad Nacional Autónoma de México, 2018.

Gutiérrez, José Antonio, El gobierno de frontera de San Luis Colotlán y sus milicias en la colonia, México, Universidad Autónoma de Aguascalientes, Universidad de Guadalajara, CU-Norte, Gobierno Municipal de Colotlán, 2010. 
Gutiérrez Contreras, Salvador, El territorio del estado de Nayarit a través de la bistoria, Compostela, Nayarit, Gobierno del Estado de Nayarit, 1979.

Gutiérrez Mendoza, Gerardo, "Hacia un modelo general para entender la estructura político-territorial del estado nativo mesoamericano", en DANEELs, GutiÉRReZ Mendoza (coords.), 2012, pp. 26-67.

Herrera Guevara, Porfirio, "Memorias de la misión de San Andrés Cohamiata en el Nayarit, escrito sin fecha, estimado entre 1853-1872”, en Relaciones, 135 (2013), pp. 127-154.

Hers, Marie-Areti, "Renovación religiosa y resistencia indígena en Nayarit. Los coras en 1767”, en Castro Gutiérrez, Guedea y Mirafuentes Galván (eds.), 1992, pp. 177-202.

Jáuregui, Jesús, "Del reino de Lozada y la segunda conquista de El Nayarit a la revolución mexicana. La resistencia cora en el movimiento lozadeño", en Participación indígena en los procesos de Independencia y Revolución Mexicana, México, Comisión Nacional para el Desarrollo de los Pueblos Indígenas, 2011, pp. 149-194.

Lira LaRios, Regina, "La organización colonial en la Sierra del Nayar, 15301722: un espacio pluridimensional”, tesis de licenciatura en historia, México, Universidad Nacional Autónoma de México, 2003.

Lira Larios, Regina, "Nuestra Madre Milpa Joven: una imagen de la totalidad efímera en un ritual wixárika”, en Journal de la Société des Américanistes, 103: 1 (2017), pp. 151-178.

LiRa LARIos, Regina, "Una lectura de la defensa territorial wixárika desde la complejidad ritual”, en Relaciones, 39-156 (2018), http://dx.doi.org/10.24901/ rehs.v39i156.315

Liffman, Paul, "The Historia of Islands. New Huichol Territorial Claims to Ancestral Places”, en Roth-Seneff, Kemper y Adrins (eds.), 2015, pp. 177-195.

López, Eucario, Algunos documentos de Nayarit, Guadalajara, Librería Font, 1978.

Lumholtz, Carl, El México desconocido: cinco años de exploración entre las tribus de la Sierra Madre Occidental, en la tierra caliente de Tepic y Jalisco, y entre los tarascos de Michoacán, México, Herrerías, 1945, 2 volúmenes. 
MAGRIÑÁ, Laura, Los coras entre 1531 y 1722. ¿̇Indios de guerra o indios de paz?, México, Instituto Nacional de Antropología e Historia, Universidad de Guadalajara, 2002.

Martínez, Lucas, "Introducción" a "Diario del comisario de misiones del Colegio Apostólico de Guadalupe, Zacatecas, 1843-1845”, en Román Gutiérrez, del Río Hernández y Carrillo Cázares (coords. y eds.), 2004, pp. 433-436.

McArdue, Michele, In the Lands of Fire and Sun. Resistance and Accommodation in the Huichol Sierra, 1723-1930, Nebraska, University of Nebraska Press, 2018.

Meyer, Jean, "El ocaso de Lozada", en Historia Mexicana, xviII: 4 (72) (abr.jun. 1969), pp. 535-568.

Meyer, Jean, Esperando a Lozada, Zamora, El Colegio de Michoacán, Conacyt, 1984.

Meyer, Jean, La tierra de Manuel Lozada, México, Universidad de Guadalajara, Centre d'Études Mexicaines et Centramericaines, 1989.

Meyer, Jean, Manuel Lozada, El Tigre de Álica: general, revolucionario, rebelde, México, Tusquets Editores, 2015.

Moreno Basurto, Samuel, "Una historia desangrada para un convento rosa. Historiografía de la exclaustración del Colegio de Guadalupe”, en Román Gutiérrez, del Río Hernández y Carrillo Cázares (coords. y eds.), 2004, pp. 329-338.

Morris, Nathaniel, “'The World Created Anew': Land, Religion and Revolution in the Gran Nayar Region of Mexico", tesis de doctorado en historia, New College, University of Oxford, 2015.

Ortega, José de, Apostólicos afanes de la Compañia de Jesús escritos por un padre de la misma sagrada religión de su provincia de México, México, Centro de Estudios Mexicanos y Centroamericanos, Instituto Nacional Indigenista, 1996.

Ortega, José de, "Maravillosa reducción y conquista de la provincia de San José del gran Nayar nuevo Reino de Toledo" (Libro 1), Apostólicos afanes de la Compañia de Jesús en su provincia de México, México, Centro de Estudios Mexicanos y Centroamericanos, Instituto Nacional Indigenista, 1996. 
Pantoja ReYes, Jose R., La guerra indígena del Nayar: 1850-1880, una perspectiva regional, México, Telar, 1995.

Peña Navarro, Everardo, Estudio histórico del estado de Nayarit de la independencia a la erección en estado, Tepic, Junta Auxiliar en Nayarit, 1956.

Pérez González, Julio, Ensayo estadístico y geográfico del territorio de Tepic, Tepic, México, Impr. de Retes, 1894.

Pinzón, Guadalupe, Acciones y reacciones en los puertos de la Mar del Sur. Desarrollo portuario del Pacífico novohispano a partir de sus politicas defensivas, 1713-1789, México, Universidad Nacional Autónoma de México, 2011.

Rojas, Beatriz, Los huicholes: documentos históricos, México, Instituto Nacional Indigenista, Centro de Investigaciones y Estudios Superiores en Antropología Social, 1992.

Román Gutiérrez, José Francisco, Leticia Ivonne del Río Hernández y Alberto Carrillo Cázares (coords. y eds.), Los colegios apostólicos de Propaganda Fide. Su historia y legado: Memoria del Congreso, Morelia, Gobierno de Zacatecas, Universidad Autónoma de Zacatecas, El Colegio de Michoacán, H. Ayuntamiento de Guadalupe, 2004.

Roth-Seneff, Andre, Robert V. Kemper y Julie Adkins (eds.), From Tribute to Communal Sovereignty. The Tarascan and Caxcan Territories in Transition, Tucson, University of Arizona Press, 2015.

SaHLins, Marshall, "The Segmentary Lineage: An Organization of Predatory Expansion”, en American Anthropologist, 63: 2 (1961), pp. 322-345.

Santoscoy, Alberto, Obras completas, Guadalajara, Gobierno del Estado de Jalisco, 1984, t. 1.

TÉLLEZ, Víctor, “Territorio, gobierno local y ritual en Xatsitsarie/Guadalupe Ocotán", tesis de doctorado en antropología social, Centro de Estudios Antropológicos, El Colegio de Michoacán, 2005.

Tello, O.F.M., Antonio, Crónica Miscelánea de la Sancta Provincia de Xalisco, Libro Segundo, Volumen III, Guadalajara, Gobierno del Estado de Jalisco, Universidad de Guadalajara, Instituto Jalisciense de Antropología e Historia, 1984. 
Thomson, Guy, El liberalismo popular mexicano, Juan Francisco Lucas y la sierra de Puebla, 1854-1917, Puebla, Benemérita Universidad Autónoma de Puebla, Instituto de Ciencias Sociales y Humanidades Alonso Vélez Pliego, Ediciones de Educación y Cultura, 2011.

Van Oosterhout, K. Aaron, "Confraternities and Popular Conservatism on the Frontier: Mexico's Sierra del Nayarit in the Nineteenth Century", en The Americas, 71: 1 (2014), pp. 101-130.

Velázquez, María del Carmen, Colotlán. Doble frontera contra los bárbaros, México, Universidad Nacional Autónoma de México, 1961.

Weigand, Phil, "El papel de los indios huicholes en las revoluciones del Occidente de México", en Ensayos sobre el Gran Nayar: entre coras, huicholes y tepehuanos, México, El Colegio de Michoacán, Centro de Estudios Mexicanos y Centroamericanos, Instituto Nacional Indigenista, 1992, pp. 121-130.

Weigand, Phil, "Territory and Resistance in West-Central Mexico. Part 2: The Rebelión de Nueva Galicia and Its Late Postclassic Prelude", en Roth-SenefF, Kemper y Adkins (eds.), 2015, pp. 71-93. 